\title{
CHRONOLOGY OF THE EARLY BRONZE AGE IN THE SOUTHERN LEVANT: NEW ANALYSIS FOR A HIGH CHRONOLOGY
}

\author{
Johanna Regev ${ }^{1,2} \cdot$ Pierre de Miroschedji $^{3} \cdot$ Raphael Greenberg $^{4} \cdot$ Eliot Braun $^{5} \cdot$ Zvi Greenhut $^{6} \bullet$ \\ Elisabetta Boaretto ${ }^{2}$
}

\begin{abstract}
The chronology of the Early Bronze Age (EBA) in the southern Levant and the synchronization between the sites, considering seriation and radiocarbon dates, have shown large inconsistencies and disagreement. We have assembled $420{ }^{14} \mathrm{C}$ dates, most of them previously published and a few provided directly by the excavators. The dates have been re-evaluated on the basis of their archaeological context and using analytical criteria. Bayesian modeling has been applied to the selected dates in relation to the given seriation of the EBA subperiods (EB I, II III, IV). Sites with 2 or more sequential subphases were individually modeled in order to define the transitions between the subperiods. The new chronology indicates that the EB I-II transition occurred site-dependently between 3200-2900 BC, with EB II-III around 2900 BC, and EB IIIIV $\sim 2500 \mathrm{BC}$.
\end{abstract}

\section{INTRODUCTION}

The Early Bronze Age (henceforth EBA; the mid-4th to end of the 3rd millennium BCE) in the southern Levant has no historical chronology of its own, and thus has traditionally relied on historical chronologies of neighboring countries, particularly Egypt. The chronological framework of Egypt has been amply discussed by scholars (Kitchen 1987, 1991; Hornung et al. 2006) and recently by Dee et al. (2009), but there is a controversy over its accuracy for the 3rd millennium BCE. A radiocarbon-based chronology for Egypt (Bonani et al. 2001; Dee et al. 2009), during a period that is roughly contemporaneous with the EBA of the southern Levant, has been recently updated by the Oxford dating projects (Bronk Ramsey et al. 2010), though the number of dates remains small. The chronological relationship between Egypt and the EBA southern Levant depends mainly upon the exchange of pottery that can be associated in Egypt with historically dated contexts, most of which are tombs (Amiran 1969; Wright 1971; Ben-Tor 1981; Mazar 1992; Braun 201 1a,b). These correlations are limited to a relatively short period in EB I and EB II, which is roughly equivalent to the very end of Dynasty 0 and Dynasty 1 . Numerous excavations in the southern Levant have yielded a significant database of stratified archaeological material, which together with ${ }^{14} \mathrm{C}$ dates can be used to build an independent chronological reassessment of the EBA period.

Previous syntheses of EBA ${ }^{14} \mathrm{C}$ dates have generally indicated slightly earlier dates than those of the traditional chronological schemes (e.g. Richard 1980; Weinstein 1984; Joffe 1993; Braun and Gophna 2004). Recent work on individual sites such as Tell esh-Shuna North for EB I (Philip 2001, 2008), Tel Yarmuth for EB I-III (Regev et al., these proceedings), the EB I-II transition at Pella (Bourke et al. 2009), and the EB II-III transition at Jericho (Bruins and van der Plicht 2001) has indicated the possibility of substantial chronological revisions. Yet, even though it has been frequently noted that newly published ${ }^{14} \mathrm{C}$ dates are often earlier than expected (Bruins and van der Pli-

\footnotetext{
${ }^{1}$ Department of Land of Israel Studies and Archaeology, Bar-Ilan University, Ramat-Gan 52900, Israel. Corresponding author. Email: johanna.regev@ymail.com.

${ }^{2}$ Radiocarbon and Cosmogenic Isotopes Laboratory, Kimmel Center for Archaeological Science, Weizmann Institute of Science, Rehovot 76100, Israel.

${ }^{3}$ UMR 7041, Archéologies et Sciences de l'Antiquité, Maison de l'archéologie et de l'ethnologie, Boîte 17, 21 allée de l'Université, 92023 Nanterre cedex, France.

${ }^{4}$ Department of Archaeology and Ancient Near East, Tel-Aviv University, P.O.B. 39040, Tel-Aviv 69978, Israel.

${ }^{5}$ Albright Institute of Archaeological Research and Centre de Recherche Français de Jérusalem, Jerusalem, Israel.

${ }^{6}$ Israel Antiquities Authority, P.O.B. 586, 91004 Jerusalem, Israel.
}

C 2012 by the Arizona Board of Regents on behalf of the University of Arizona Proceedings of the 6th International Radiocarbon and Archaeology Symposium, edited by E Boaretto and N R Rebollo Franco RADIOCARBON, Vol 54, Nr 3-4, 2012, p 525-566 
cht 2001; Golani and Segal 2002; Golani 2004; Anderson 2006; Holdorf 2010), a general overview of all available EBA dates related to published cultural material has not been previously attempted. The present paper attempts to fill that lacuna through a comprehensive review and reassessment of the evidence in hand.

\section{THE EARLY BRONZE AGE OF THE SOUTHERN LEVANT}

Traditionally, the Early Bronze Age (EBA) in the Levant is divided into 3 subperiods (designated EB I, EB II, EB III) with a fourth division, EB IV, often designated as a separate period (e.g. Intermediate Bronze Age, EB-MB, or MB I in different systems of terminology). In the southern Levant, the EBA phases are sometimes divided into subphases (e.g. EB IA, EB IB, etc.), based either on pottery typologies or local stratigraphic sequences (Amiran 1969; Wright 1971; Richard 1987; Mazar 1992; Stager 1992; see also Braun 2012).

\section{Early Bronze I (EB I)}

The earliest phase of the Levantine Bronze Age, often termed Early Bronze IA, has only recently come into its own as an archaeological entity. Post-Chalcolithic in terms of social and economic organization, it is also quite distant from the agglomerated village society that paves the way to urbanism in late EB I. Early EB I settlement may be characterized as extensive rather than intensive, dispersed rather than agglutinative. Social formations were small and segmented; craft specialization and long-distance contacts were limited.

Later EB I (or EB IB) represents the coming of age of EBA village society. These villages dot the landscape and had significant populations in some regions. A very few grow to significant sizes (20 ha and upwards), taking on some functions of regional centers. Large cemeteries appear, characterized by multiple burial tomb-caves. Ceramic industries are marked by regionally distinctive styles and fabrics. Several settlements with assemblages of Egyptian material culture in the southwestern region offer good chronological associations between Egypt and the southern Levant.

The end of EB I and the beginning of the succeeding EB II period are intertwined with historical events in late predynastic and early dynastic Egypt. The transition from EB I to EB II has been correlated with a timespan between the reigns of the first and third kings of Dynasty 1 (Braun 2001, 2011a,b).

The date ranges recently suggested for EB I are 3500-3050 BC (de Miroschedji 2006) and 3500 $3150 / 2950 \mathrm{BC}$ (Braun and Gophna 2004). Based on ${ }^{14} \mathrm{C}$ dates in Ashqelon Area E, Golani (2004) has proposed an earlier date for the beginning of $\mathrm{EB}$ IA, closer to $3800 \mathrm{BC}$, similar to the date of 3700 suggested by Yekutieli (2007), based on ${ }^{14} \mathrm{C}$ dates from a cluster of sites at Ashqelon. These early dates for the beginning of the EB IA are consistent with the high ${ }^{14} \mathrm{C}$ dates obtained for the preceding Late Chalcolithic (Bourke et al. 2001, 2004; Burton and Levy 2001; Joffe and Dessel 1995; Klimscha 2009). The differences in chronology for the EB I are mostly due to how the ${ }^{14} \mathrm{C}$ dates are associated with the archaeological contexts they purport to date (Boaretto 2007), which Egyptian chronology is used, and the way their correlations with south Levantine chronology are interpreted.

\section{Early Bronze Age II (EB II)}

The transition to EB II is marked by significant changes in settlement distribution, site size and organization, household architecture, subsistence practices, and material culture. There are fewer sites in all regions, and they are usually large, densely built up, and fortified. During this transition, ceramic industries become more centralized, while there are fewer regional variations. In the northern 
region, North Canaanite Metallic Ware (NCMW), produced in centralized workshops (Greenberg and Porat 1996), is the dominant ceramic industry. Examples of this ware, alongside other south Levantine imports, have been found in 1st Dynasty tombs in Egypt from the time of Djer (Kantor 1992; Adams and Porat 1996; Sowada 2009).

The transition between EB II and EB III is not as clearly connected to Egyptian chronology due to the cessation of trade connections between the regions from the 2nd Dynasty onwards. Thus, the traditional correlation of later EB II with the 2nd Dynasty (Mazar 1992; de Miroschedji 1999), or even the 3rd Dynasty (Joffe 1993), is based on virtually no material evidence.

\section{Early Bronze Age III (EB III)}

During the EB III, the urbanization process, begun in EB II, appears to intensify as some settlements grow larger and more elaborate structures are added to urban and urban-like communities (de Miroschedji 1999). By the late EB III, localized episodes of growth and decline may have created an attenuated landscape composed of a few heavily fortified centers and a large "invisible" mobile component that would later acquire the form of dispersed, rural/pastoral Intermediate Bronze Age settlement.

There are several important walled sites - no more than a dozen in all - that show long stratigraphic sequences. These centers are often highly fortified. They exhibit new features illustrative of elite aggrandizement and creation of wealth and status disparities: palaces (Yarmuth, Megiddo), monumental temples (Megiddo, Ai, Khirbet ez-Zeraqun), and ostentatious elements of material culture (e.g. outsized platters, apparently used in competitive feasting), suggestive of a more highly developed ideology of social stratification. Many other sites, however, have fewer strata and seem to cover only part of the sequence, particularly its earlier part. This is especially true of the highlands east of the Jordan, where urbanism never quite attained the peaks seen to the west (Philip 2001).

Pottery traditions are quite uniform in the region in EB III, although they are no longer produced in centralized workshops. Only a brief and geographically limited episode of external influx is evident in the material culture, represented by the introduction of Khirbet Kerak Ware of apparent Early Transcaucasian origin, which becomes one of the hallmarks of EB III in the north.

EB III is traditionally defined as coinciding with dynasties 3-6 (Mazar 1992; de Miroschedji 1999). These correlations, however, have no secure material basis. The end of the period is conventionally placed around 2300 BC (Mazar 1992; de Miroschedji 1999), during the reign of Pharaoh Pepi I, when there is evidence of Egyptian military intervention along the southern Coastal Plain of Israel (de Miroschedji 2012). The date of Pepi's reign, however, is disputed and could be somewhat earlier (Bronk Ramsey et al. 2010).

\section{Early Bronze Age IV (EB IV) or Intermediate Bronze Age (IBA)}

This is a period of de-urbanization or breakdown of urban society and a return to a more egalitarian, village and hamlet lifestyle. EB III urban settlements are all abandoned. At a handful of major tells west of the Jordan River, minor reoccupations follow abandonment of EB III cities. For the most part, however, EB IV settlements were founded at new locations, usually as small unfortified villages abandoned by the end of the period. East of the Jordan River, there is more evidence for EB III-IV continuity.

Pottery styles become, once again, highly regionalized, yet nearly always easily distinguishable from both earlier and later periods. An interesting element is the appearance of a Syrian-inspired 
drinking set (cups, teapots, and beakers) that can be linked to ceramic industries of the last third of the millennium in Syria proper, joining other elements that connect EB IV societies of the southern Levant with contemporary Syria (Bunimovitz and Greenberg 2004).

EB IV (Intermediate Bronze Age) is conventionally ascribed to 2300/2250-2000 BC (Mazar 1992), in correlation with the First Intermediate period in Egypt and the later part of Syrian EB IV. A period of 2400/2350-2000/1950 is preferred by Richard (1980), and an end date of $1925 \mathrm{BC}$, which is well after the beginning of the 12th Dynasty, was suggested by Cohen (2002).

\section{SITES, CONTEXTS, AND SAMPLES}

A total of 420 dates were compiled from 57 sites. Of these, 60 samples originate from sites in the arid zone (Avner and Carmi 2001), whose material culture assemblages are difficult to assign to a particular EB subphase. The remaining $360{ }^{14} \mathrm{C}$ dates were compiled from 41 different sites or clusters of sites in the southern Levant (see Table 1 and Figure 1). All results have been calibrated using OxCal v 4.1.6 (Bronk Ramsey 2009) and the IntCal09 calibration curve (Reimer et al. 2009).

For the EB I period as a whole, there are 125 samples. These are further subdivided, according to most excavators' determinations, into EB IA (57 samples) and EB IB and "final EB IB" (60 samples), with 8 samples designated as transitional EB IA/B. Note that for some excavators, EB IB is part of the EB I period proper, while "Final EB IB" can also be considered as the beginning of EB II. For the other periods, only the major division was used in this study, namely EB II (93 samples), EB III ( 78 samples), and EB IV ( 27 samples) periods. The remaining 37 dates could not be assigned to any specific period. The associations of the dates to archaeological phases assigned by the excavators were reviewed by the authors, as follows: EB I by E Braun; EB II by R Greenberg; EB III by P de Miroschedji; and EB IV by Z Greenhut.

The accuracy and precision of the ${ }^{14} \mathrm{C}$ dates depend, first and foremost, on the certainty of their direct association to specific, well-defined archaeological contexts, then on any degree of error introduced during their analytical processes, including sample preparation and measurement. While the latter factors are independent and contribute to the final accuracy and precision of a ${ }^{14} \mathrm{C}$ date and its interpretation, only a correct association of a sample to an archaeological context means that the date will provide meaningful results (Boaretto 2007).

The dates used in this study were collected from various published and unpublished sources, implying a great deal of variation in the quality and completeness of the published archaeological record associated with them. Often, the exact location and contexts of the samples remain obscure. In addition, the level of stratigraphic disturbance at different sites and excavation squares varies greatly, affecting the primary reliability of samples. Moreover, there are differences in the terminology used by different excavators for particular EB periods or phases. For example, a phase designated by one excavator as EB IB might be identified by others as early EB II. Where information on the exact find spots of samples is unavailable, and they cannot be directly associated with diagnostic material-culture inventories, we rely on the word of the excavator as to which specific EB phase the sample is to be attributed. Taking all these considerations into account, we have decided nevertheless to collect all available dates, recalibrate them, and identify obvious outliers by modeling and by evaluating stratigraphic contexts. The result provides a baseline for future study, and highlights areas that require further attention. 


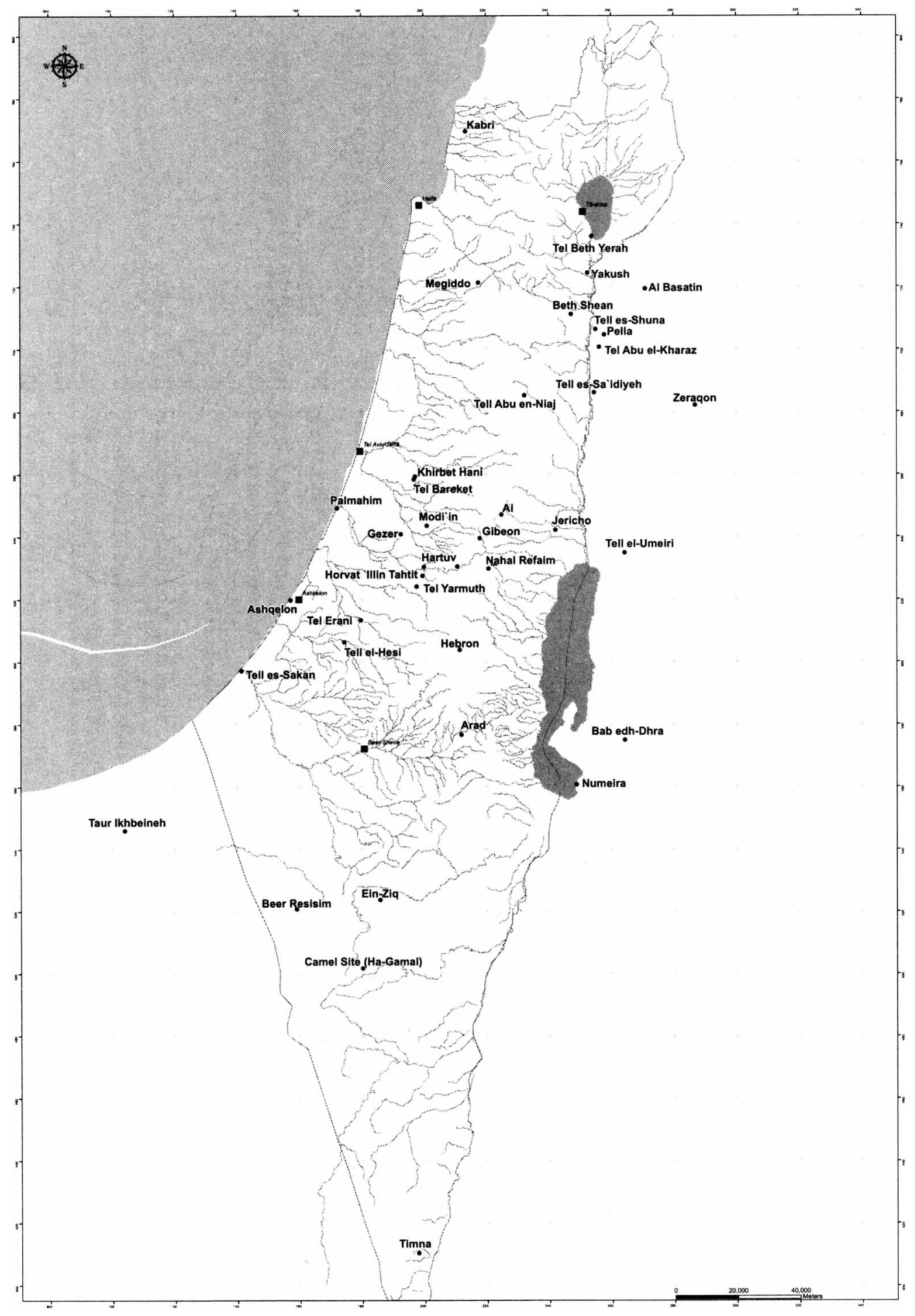

Figure 1 Map of the EBA sites included in this study 


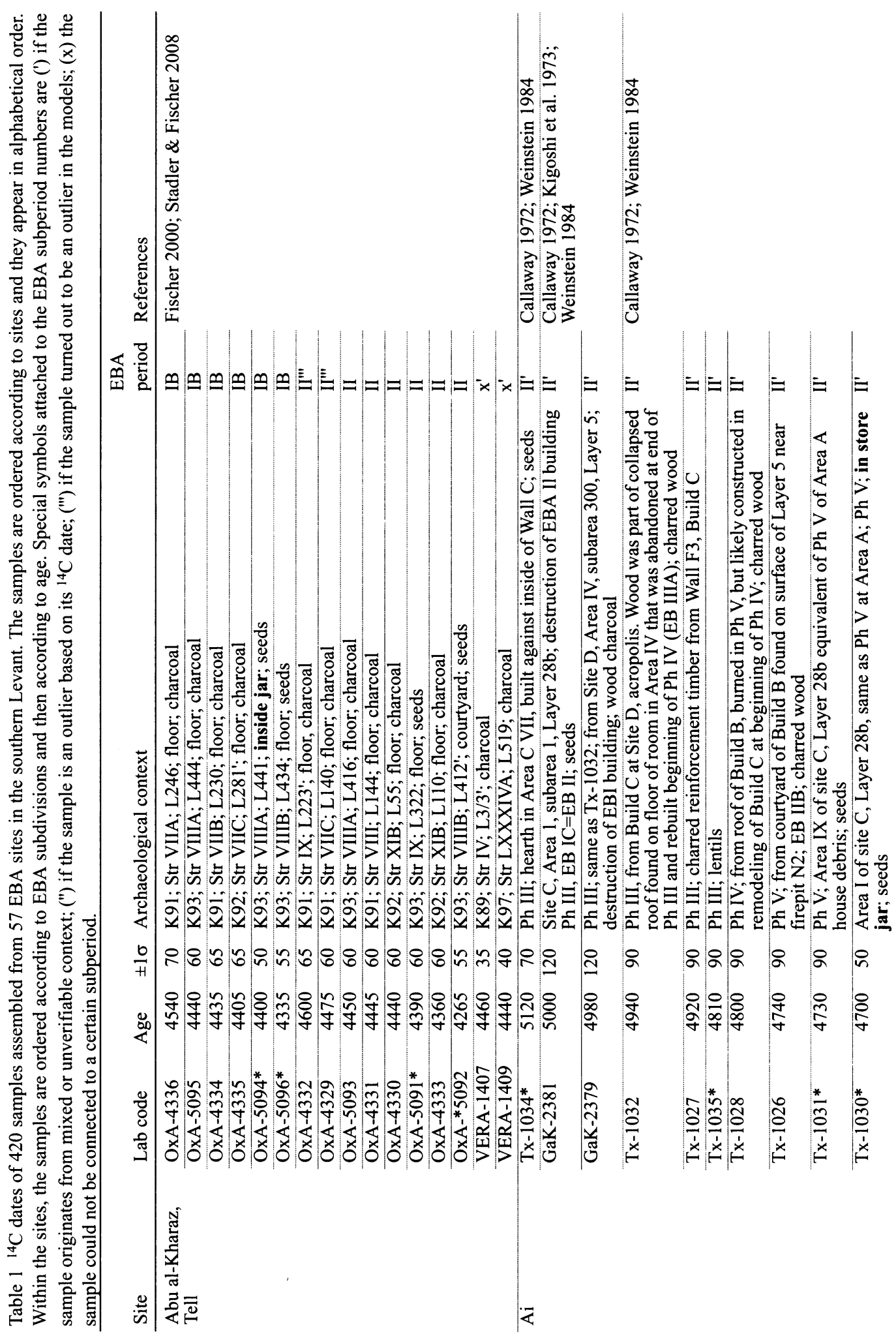




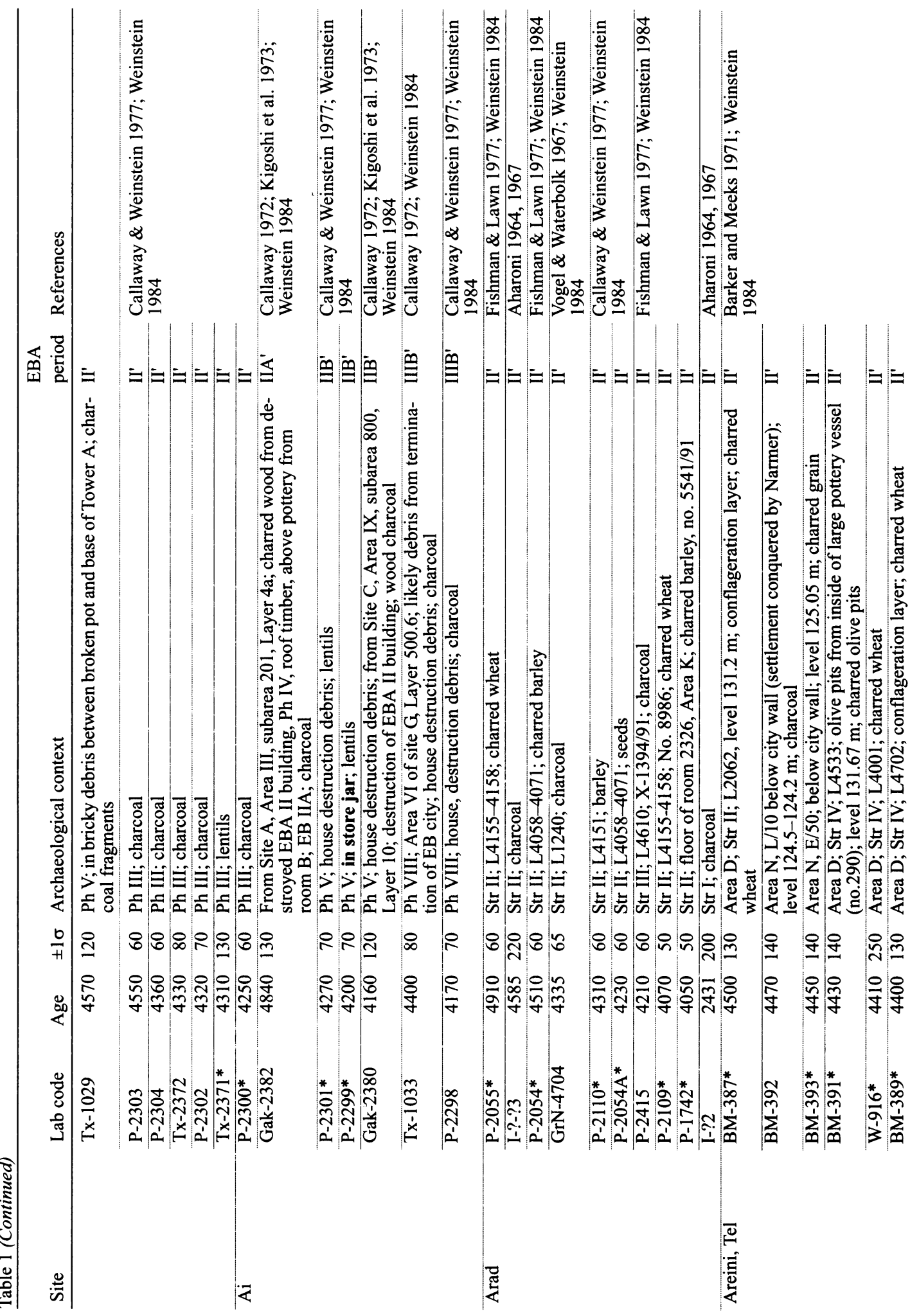




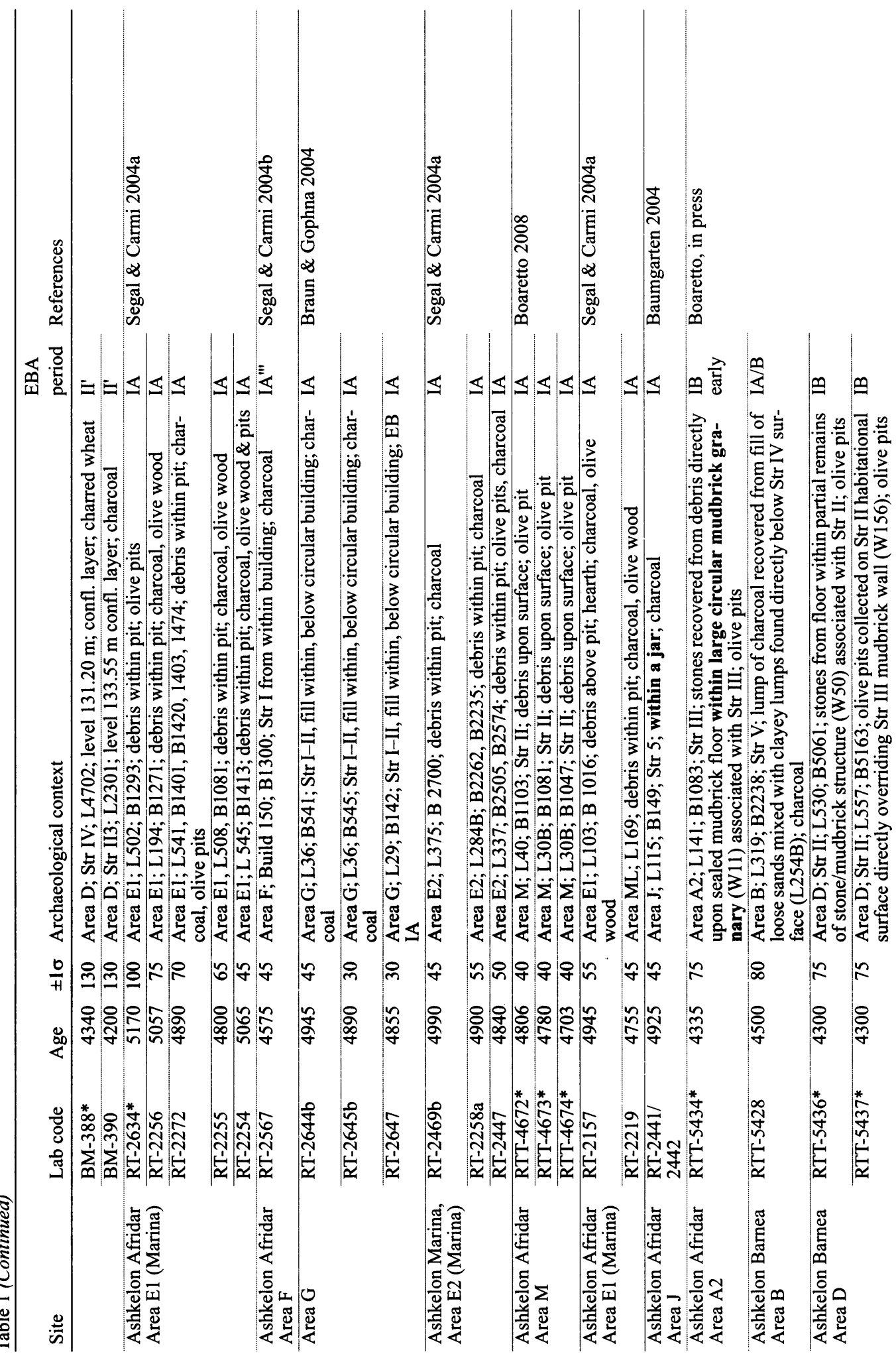




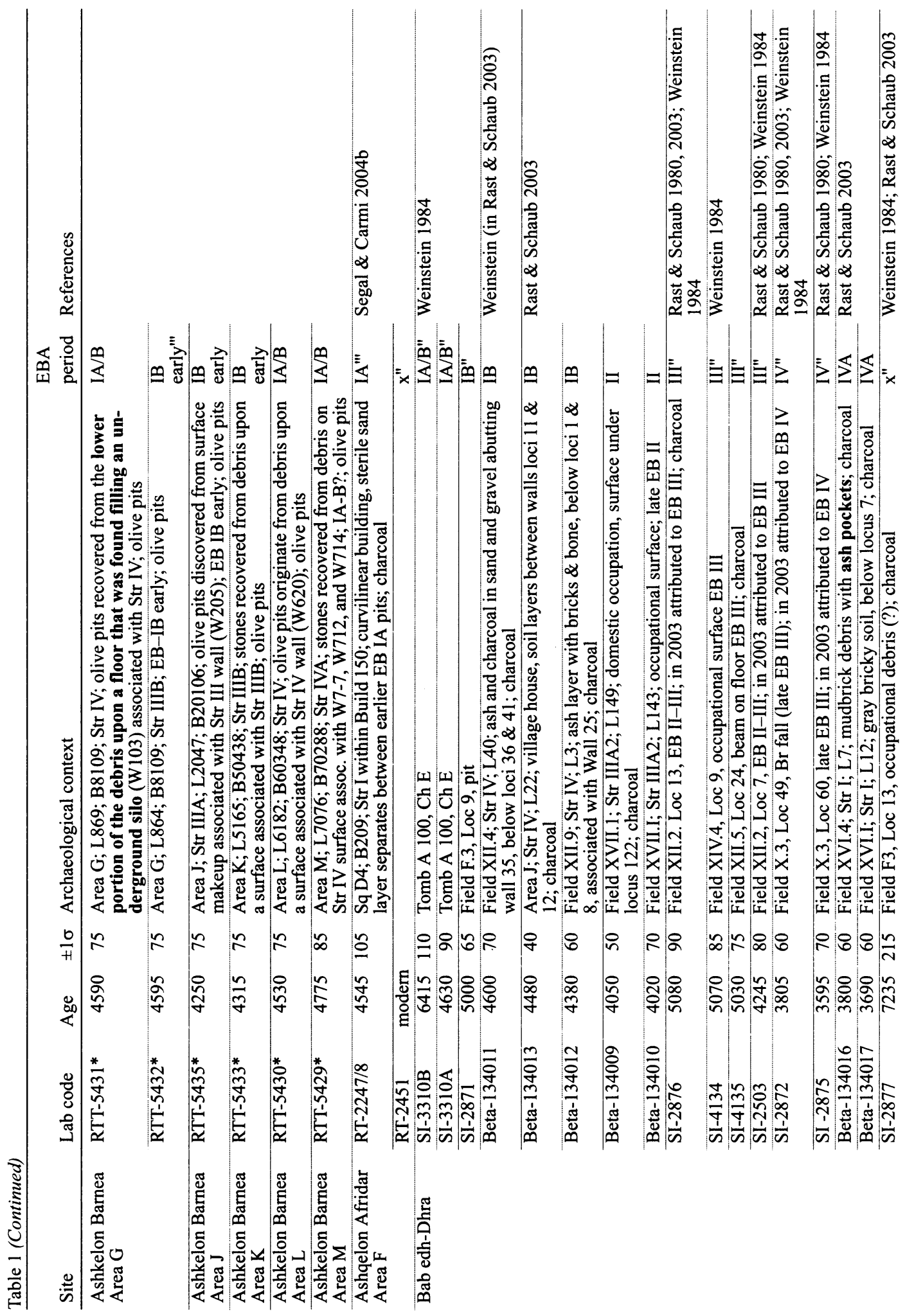




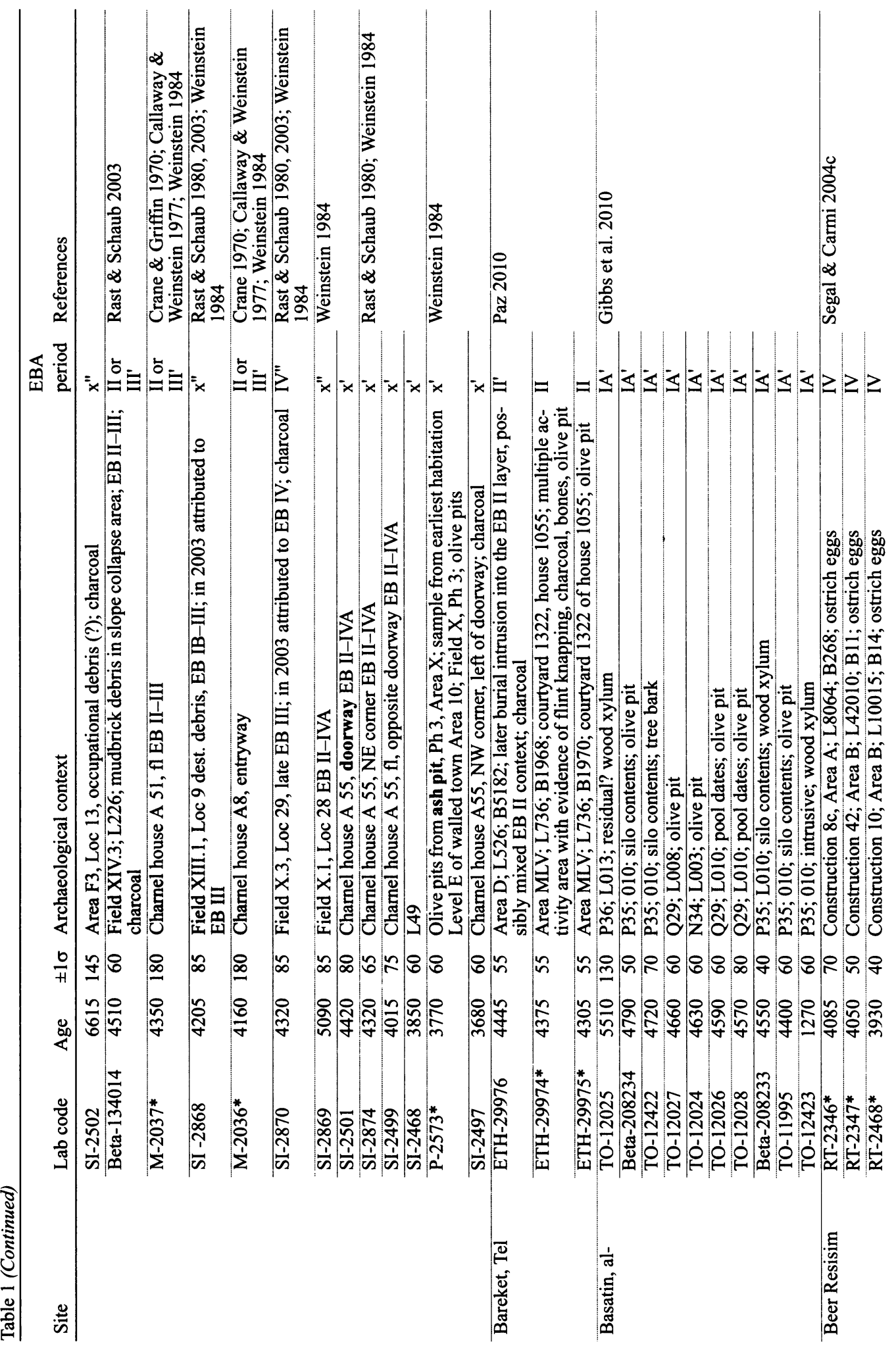




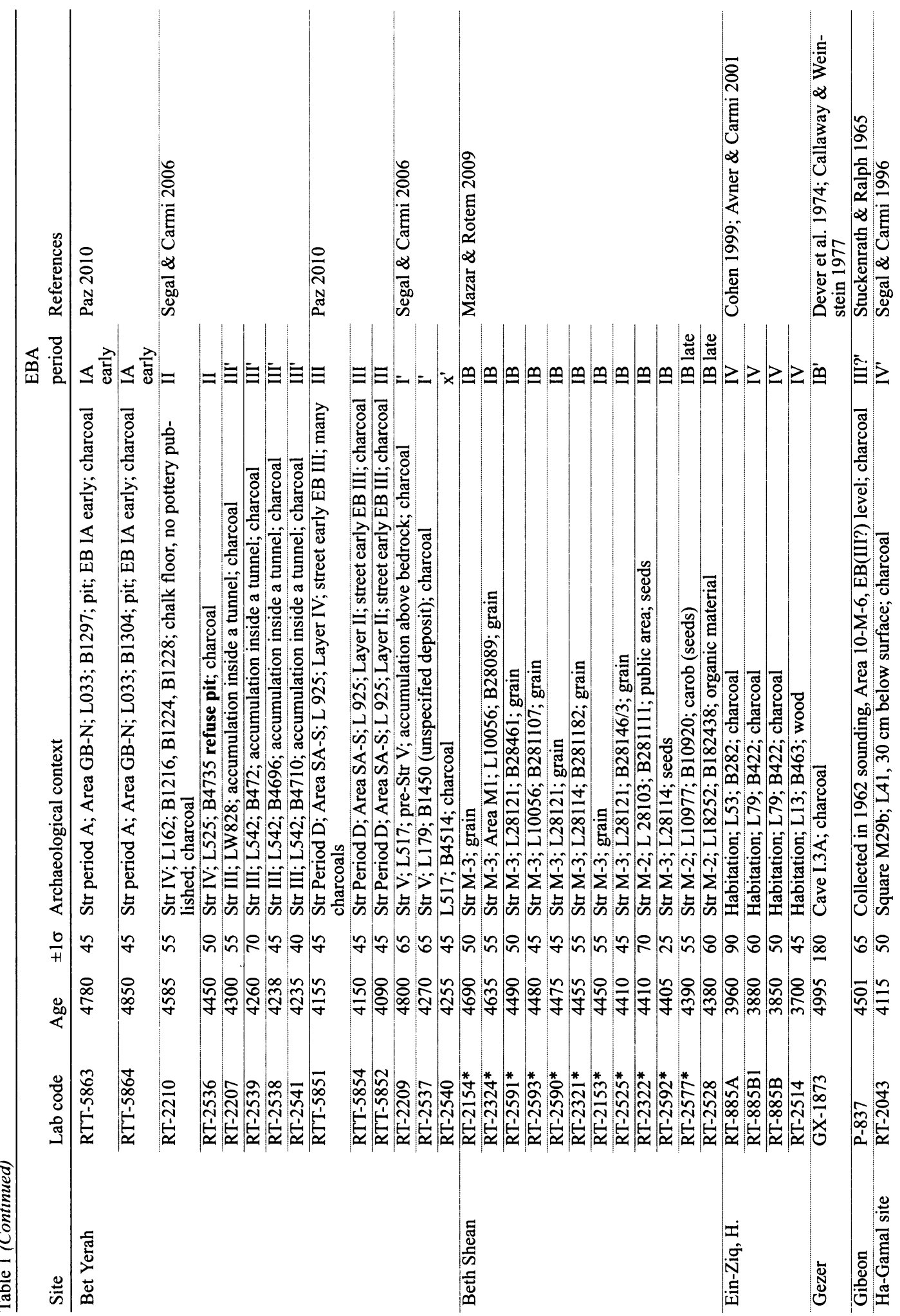




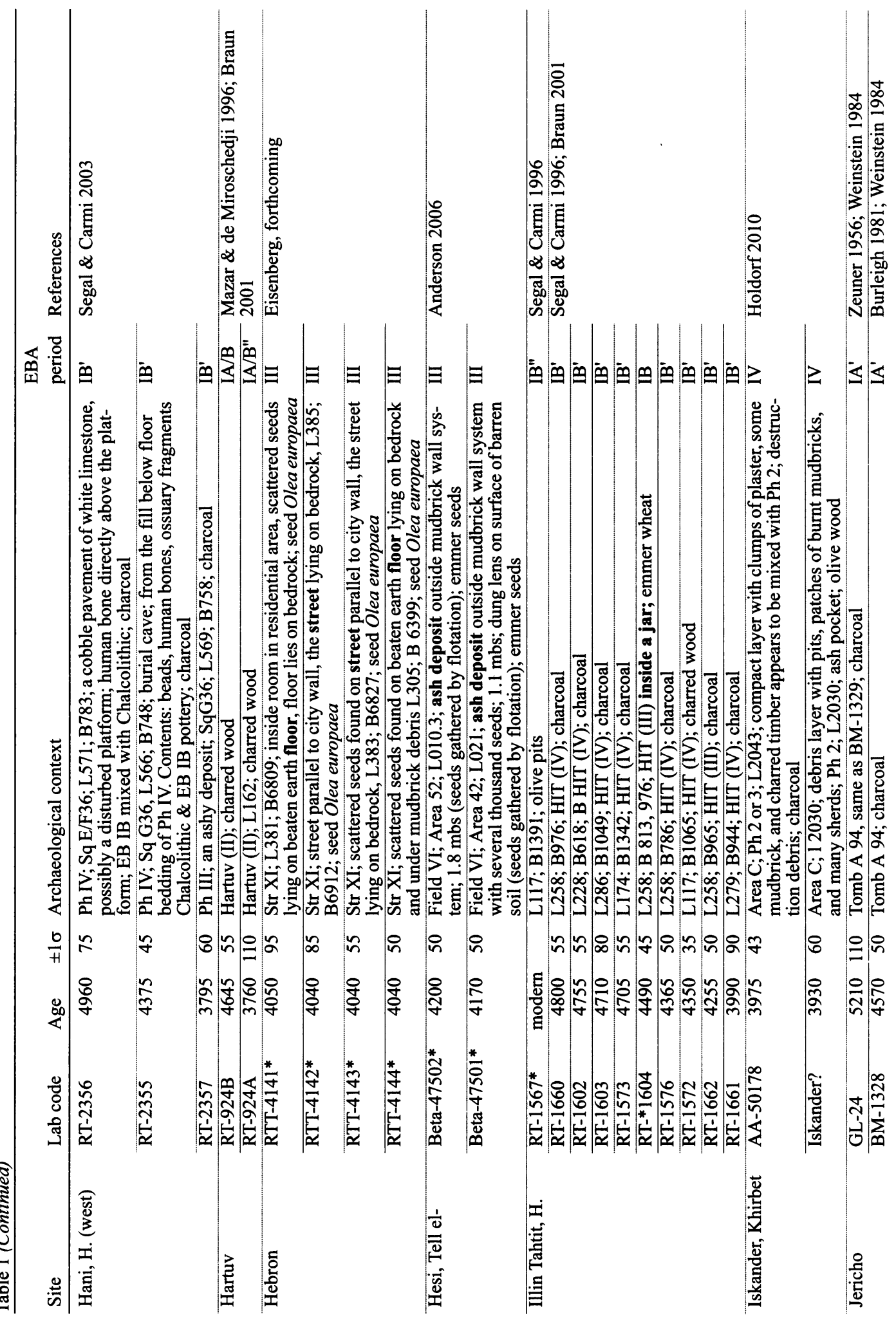




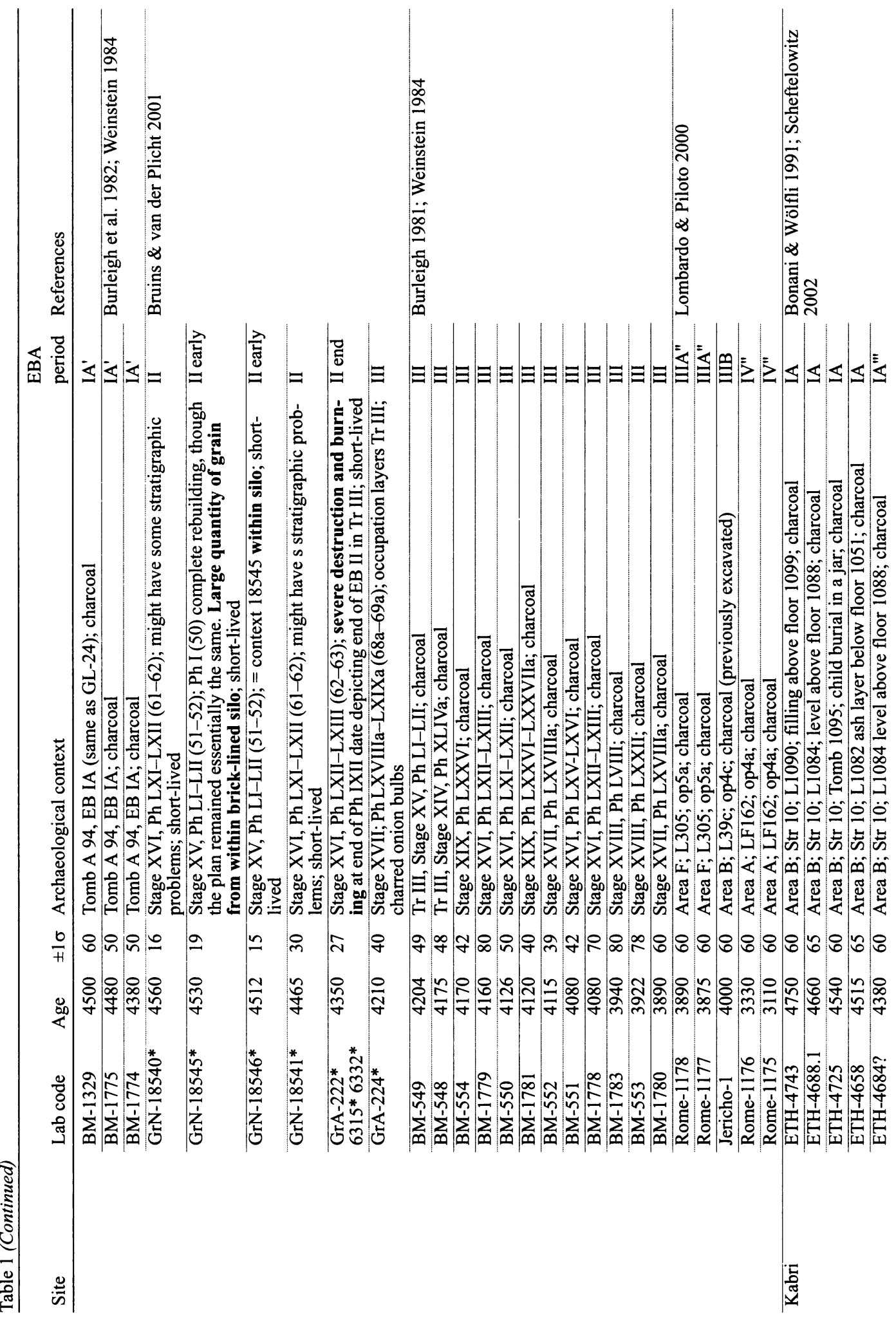




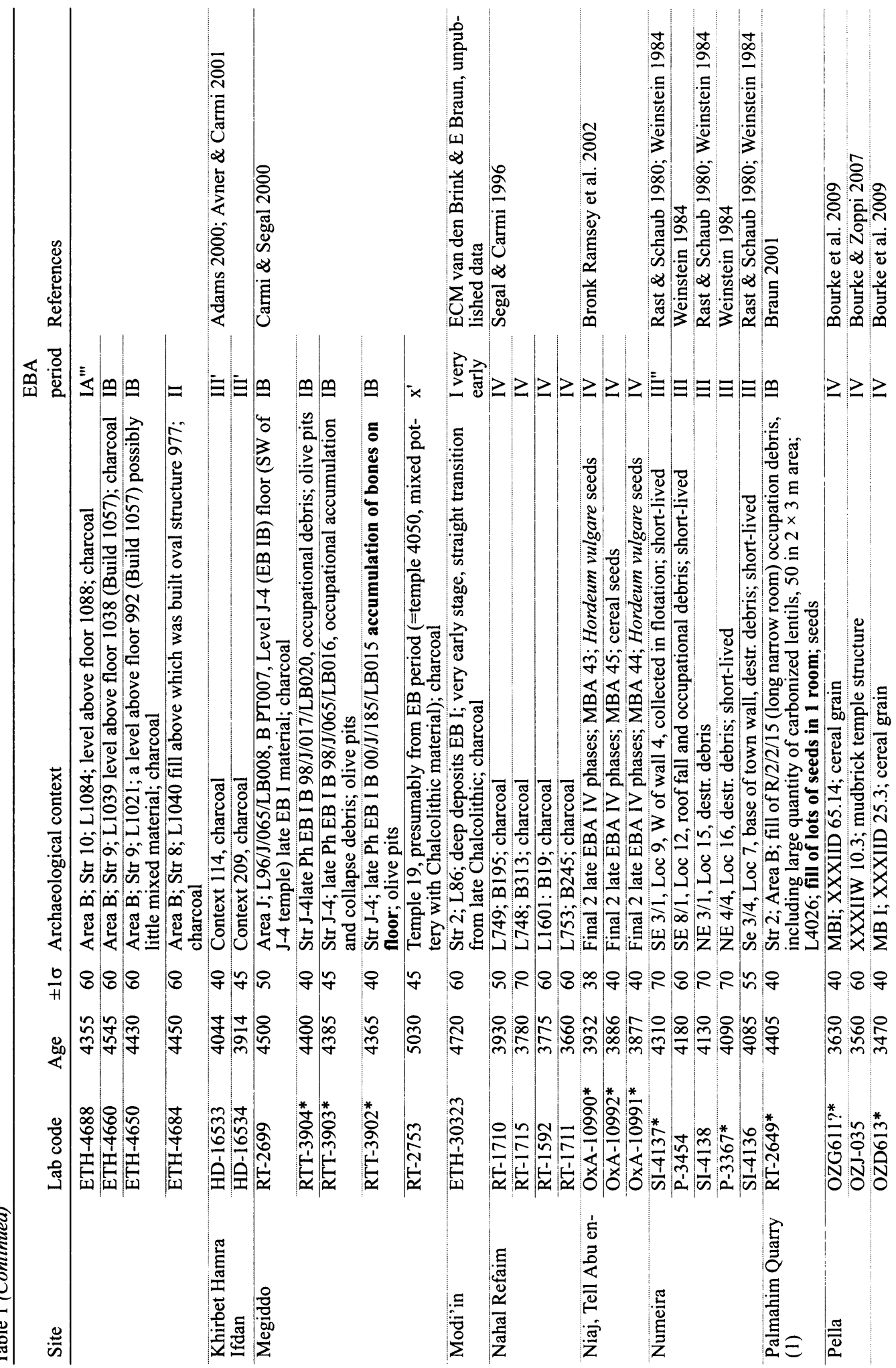




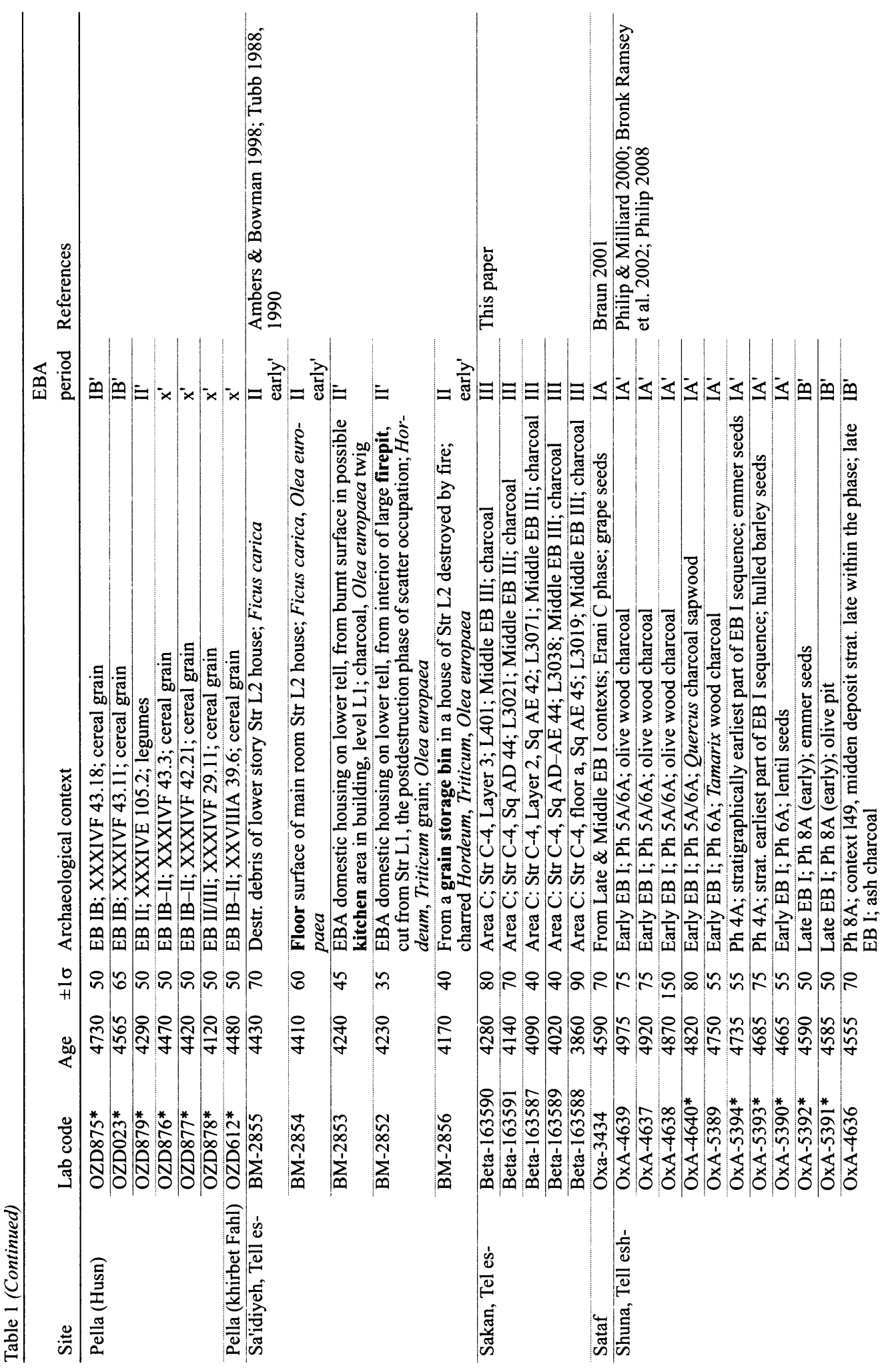




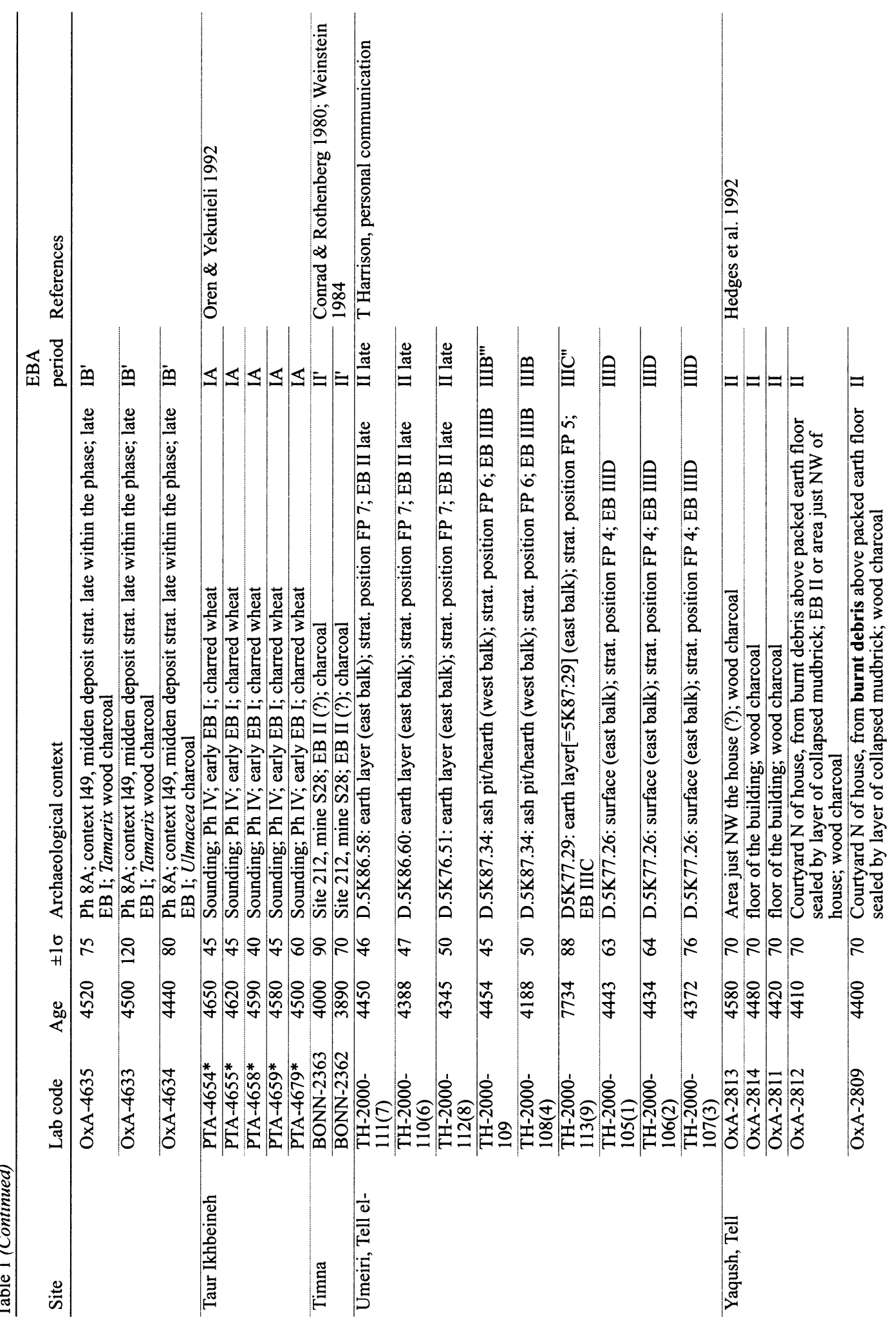




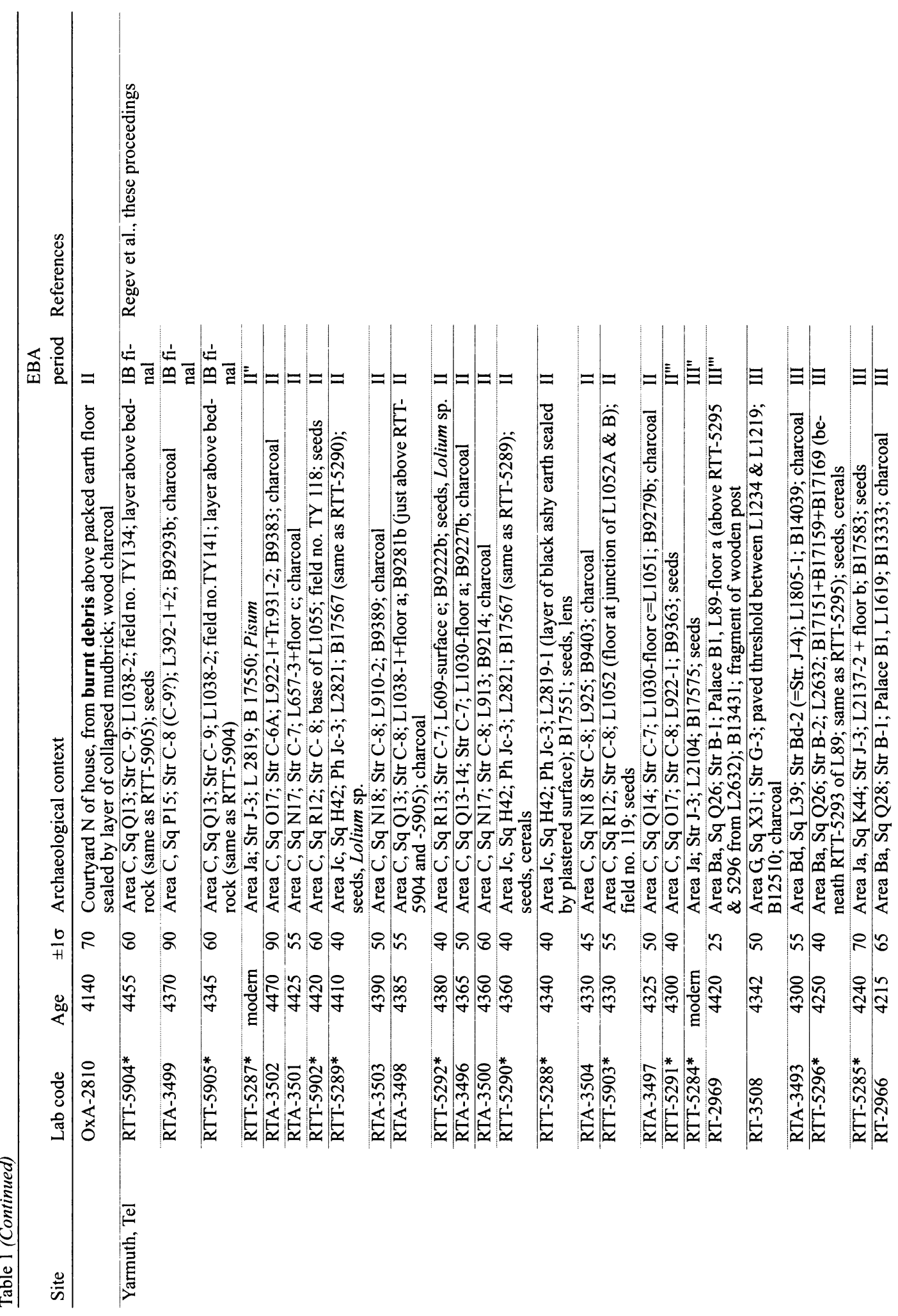




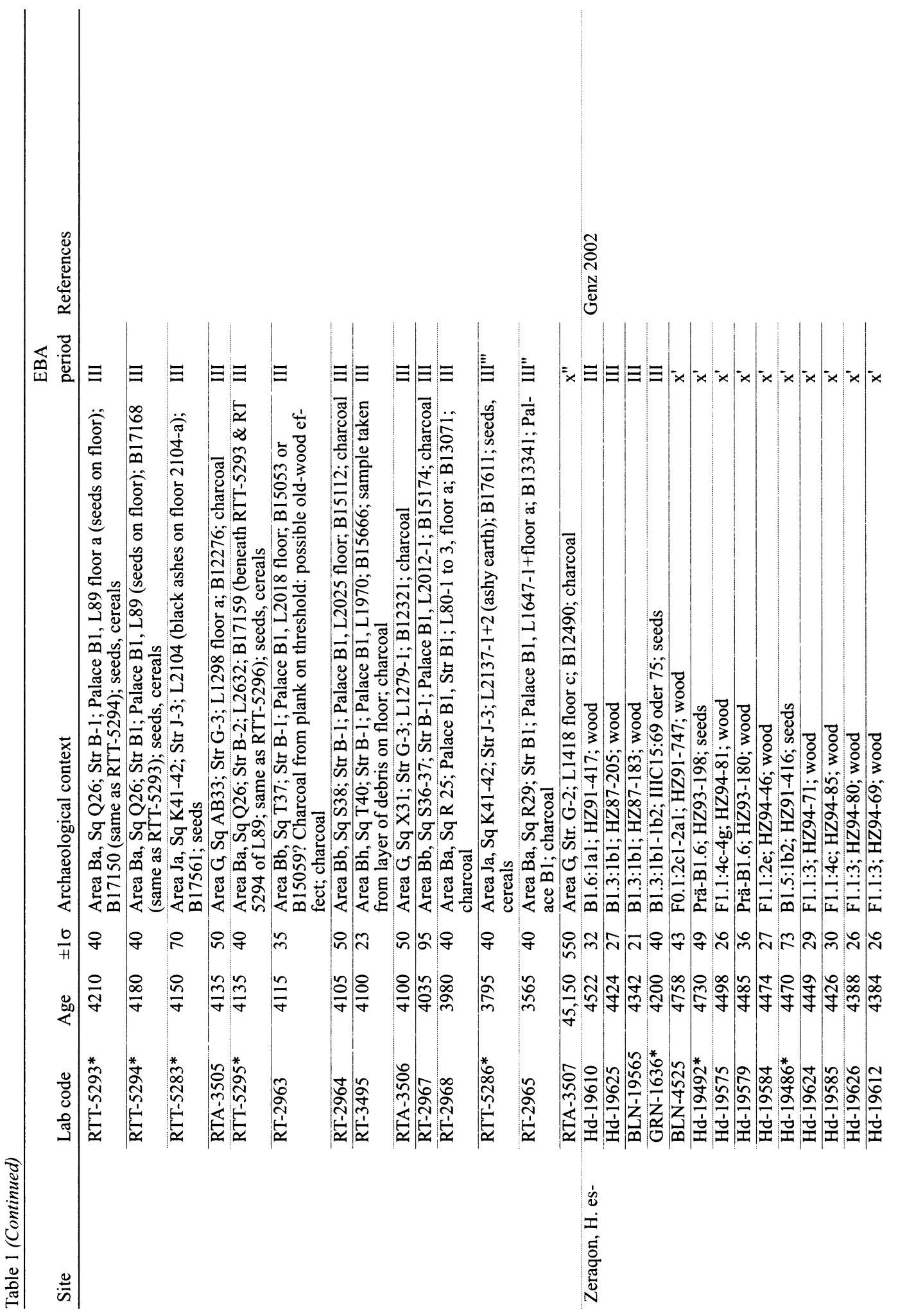




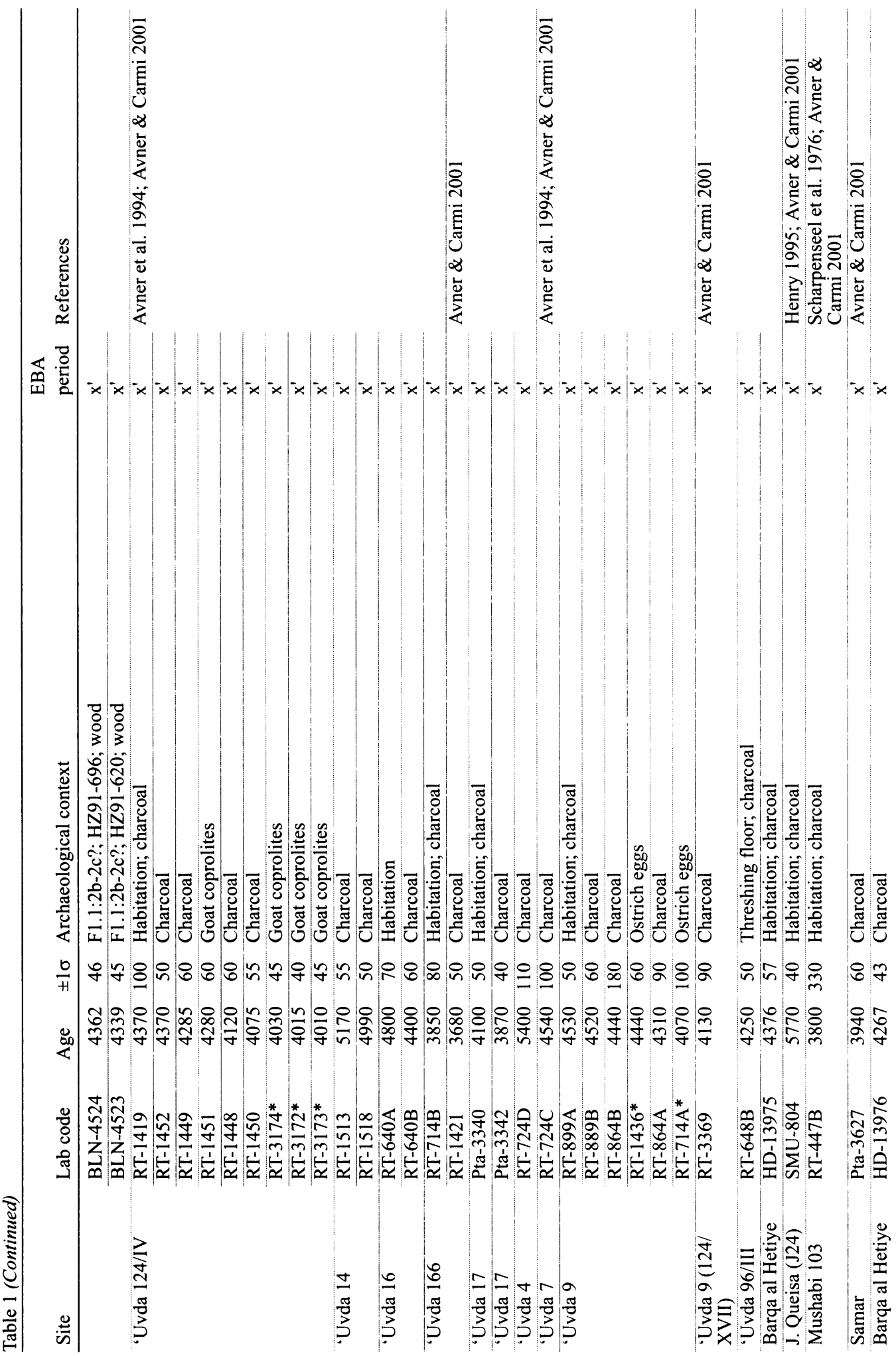




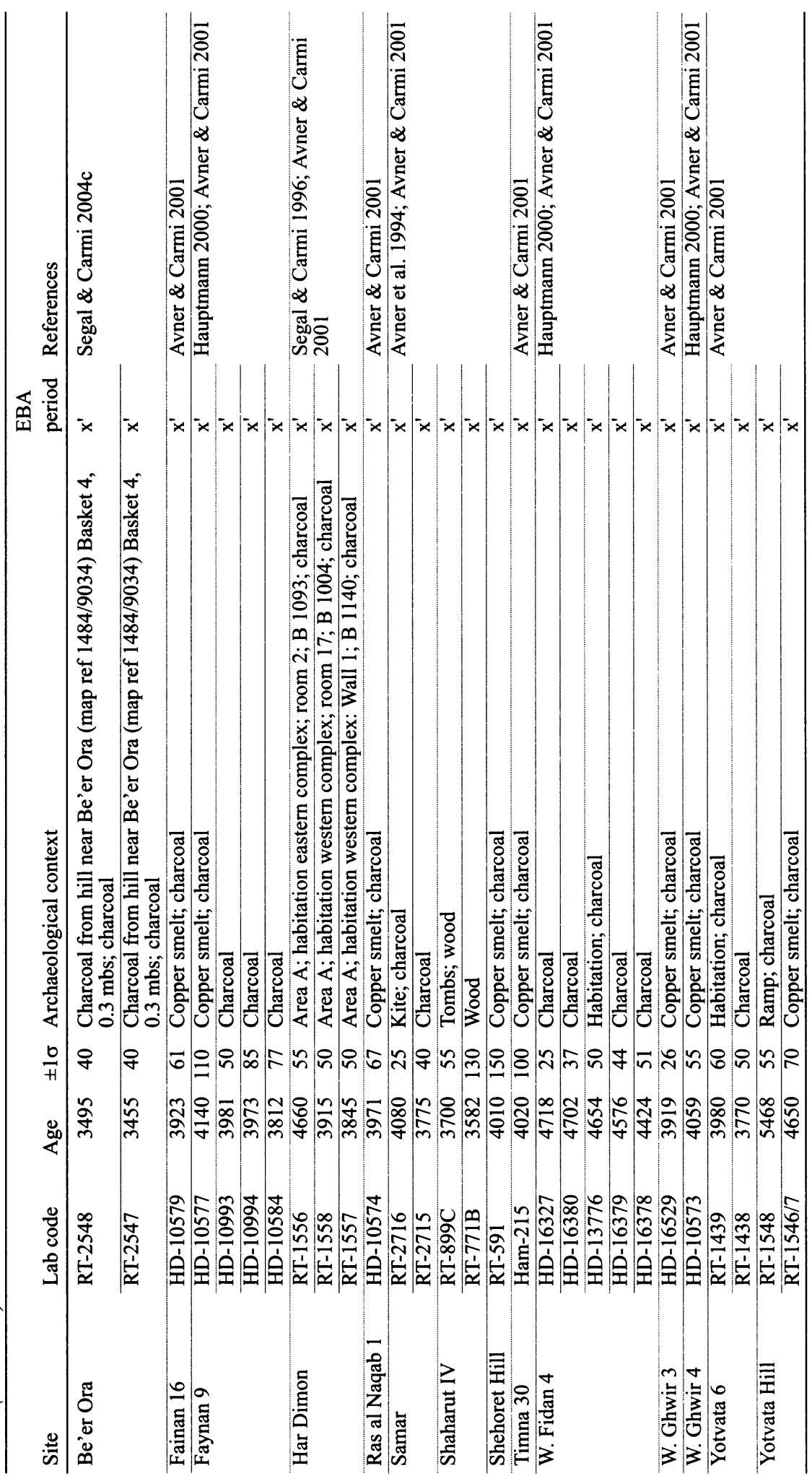


The 420 samples include 139 from short-lived (e.g. seed, cloth, goat coprolite, and eggshell) and 270 from long-lived (e.g. wood charcoal and wood) sources. For 11 samples, this information is lacking. While there is a general consensus that short-lived samples provide higher accuracy for dating the context than long-lived samples, it is necessary to determine if short-lived samples, and in particular seeds, were grouped in clusters or scattered in archaeological sediments. We have not, $a$ priori, discarded single seeds as intrusive or residual, but have assiduously attempted to determine whether there is a reliable association between them and their contexts. Wood charcoal or wood is recognized to be less accurate because of the well-known "old wood" effect (Schiffer 1986; Bowman 1990; Ashmore 1999). However, if their contexts can be securely attributed to specific archaeological deposits, and especially when they originate from the end of a phase, they will provide a terminus post quem for the following phase. This is very useful in modeling. In addition, charcoal from hearths, i.e. originating from shrubs or small trees with fast growth rates, may not suffer from the old-wood effect. When possible, separate models were run for seeds only, to find out the significance of the old-wood effect.

Particularly good contexts for a ${ }^{14} \mathrm{C}$ sample are seeds found inside closed containers, such as granaries, jars, fireplaces, tabuns (ovens), within destruction layers, and bones in articulation. In our study, there are very few contexts of this type: 10 samples only could be identified as coming from storage installations or jars. No bones were dated.

The samples were measured over many decades using different techniques and in a number of laboratories. Of the 420 samples, 262 were measured by decay counting and the rest by accelerator mass spectrometry (AMS). Details on chemical pretreatment or measurement for the samples can be found in the references reported. In particular for Ashqelon, Bet Yerah, Hebron, Megiddo, and Tel Yarmuth, dated by the Radiocarbon Laboratory at the Weizmann Institute, details about the procedure are reported in Yizhaq et al. (2005).

\section{RESULTS}

All the samples that could be related to a specific non-mixed, chronocultural phase by the excavators, and that provided ${ }^{14} \mathrm{C}$ measurements that spanned between $4000-2000 \mathrm{BC}$, were assembled in a plot (Figure 2). Out of the 323 culturally definable dates, 10 samples were out of the 2000-4000 $\mathrm{BC}$ date range, and thus excluded from the chart giving all the dated EBA samples. This plot includes 313 dates from 41 sites, and is based on the ${ }^{14} \mathrm{C}$ dates in Table 1 (the sites are alphabetically ordered). Archaeological periods in the plot are represented by colors, each individual line depicting a single date plotted as $\pm 1 \sigma$ calibrated range $\mathrm{BC}$.

\section{Removal of Samples with Unclear Stratigraphic Contexts}

Removal of some samples or removal of a complete site from further analysis and modeling was done by the authors on the basis of contextual and/or archaeological considerations, usually because of incomplete or unavailable documentation. Samples measured long time ago, were also removed. Our considerations for excluding specific samples from the study are briefly reviewed below.

The site of Ai was removed since it is not possible to correlate samples with secure pottery assemblages. Samples from Arad were not used since no basket numbers are given that would provide additional information on material found in association with the dated samples, as the locus numbers alone could not sufficiently supply the ceramic information needed. The very earliest dates from Ashqelon EB IA are questionable, since the site also had a Chalcolithic occupation, and the pottery associated with the earliest dates could be mixed EB and Chalcolithic assemblages (Braun and 


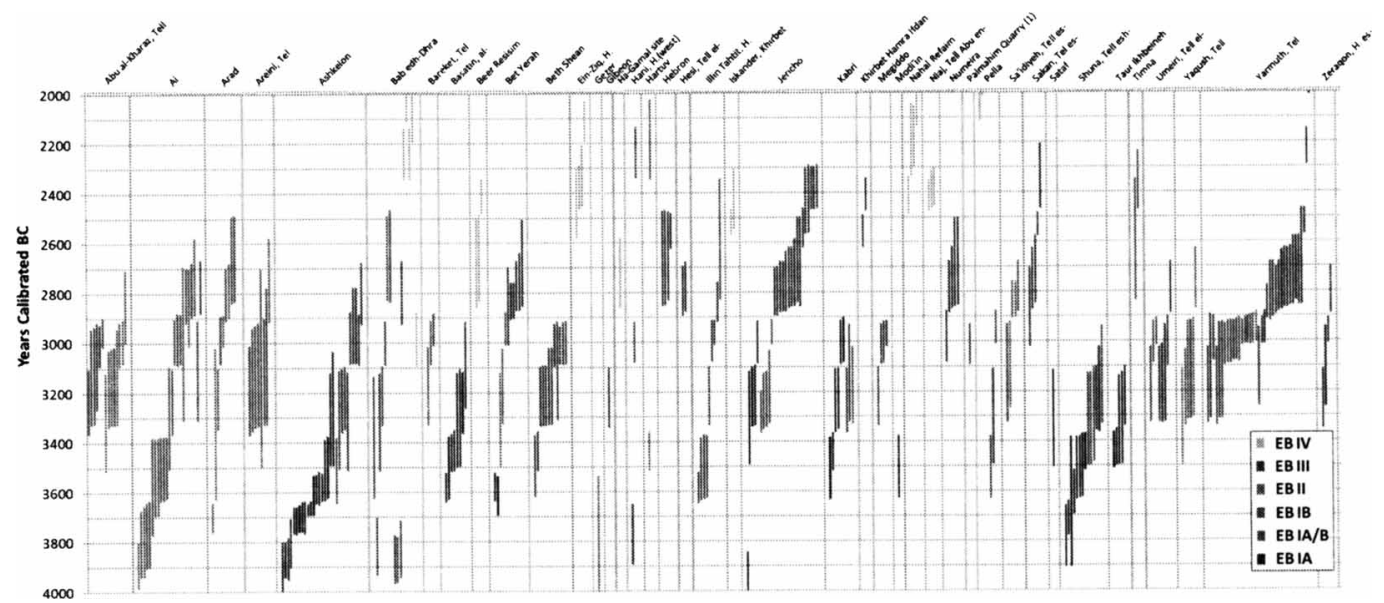

Figure 2 Calibrated ${ }^{14} \mathrm{C}$ dates of 313 samples from 41 sites, all samples that could be attributed to EBA subphases. Each line depicts a single ${ }^{14} \mathrm{C}$ measurement with $\pm 1 \sigma$ range and is colored according to its archaeological subphase (see legend).

Gophna 2004). However, those dates are left in the analysis. The dates published in 1984 from Bab edh-Dhra are not considered secure. Some originate from tombs that were reused over time and thus represent chronological ranges, and some derive from contexts with mixed period pottery assemblages. Thus, only the dates from the 2003 publication were considered reliable. At Beer Resisim, contexts are considered secure, but it should be noted that the material dated derived from ostrich eggshells. Notably, ${ }^{14} \mathrm{C}$-dated ostrich eggshells from Egypt systematically produced older ages (Wuttman et al., these proceedings). At Beth Yerah, the dates from the excavations of Getzov attributed to EB I and EB III were not used due to insecure contexts (a fill of a tunnel and unspecified contexts). The site of Tel Erani has not been properly published and therefore ${ }^{14} \mathrm{C}$ dates cannot be placed in well-defined contexts. The ${ }^{14} \mathrm{C}$ dates from this site also have large laboratory errors. Determinations from a cave at Gezer were removed since their context was associated with pottery of different periods, while others from Gibeon come from an old excavation for which there is no contextual information. At H. Hani, the burial context is mixed with Chalcolithic material, and was thus removed. Hartuv has yielded 2 dates for the same phase more than $1000 \mathrm{yr}$ apart, while samples originating from tombs at Jericho (Tell es-Sultan), which were used over an extended period of time, were also discarded. At Kh. ez-Zeraqun, only 4 dates out of 16 (Genz 2002) are securely connected to the EB III horizon, while the remainders were discarded as being suspected of old-wood effects (H Genz, personal communication). The EB IA and EB IB dates of the site of Tell esh-Shuna and alBasatin, the EB IB and EB II dates from Pella, and the EB II dates from Tell es-Sa'idiyeh are not included in the "good contexts" since not enough has been published on the ceramic assemblage related to the samples to enable independent evaluation of the chronocultural horizons. However, as the material originates in well-controlled excavations, the results are mentioned, where relevant.

The dates from arid zones in the south, published by Avner and Carmi (2001), are not considered in this work as the material culture connected with them is meager and incompletely published. Thus, it is either difficult or impossible to directly correlate the samples with various periods and phases of the Early Bronze Age.

As a result of this culling, of the total $313{ }^{14} \mathrm{C}$ dates available (Figure 2), 99 samples were removed due to purely archaeological considerations, leaving 214 dates originating from 29 different sites. An additional 14 samples were removed as clear outliers based on ${ }^{14} \mathrm{C}$ data, thus leaving a total of 200 samples for further analysis. 


\section{Modeling Methods for the Early Bronze Age}

Modeling was performed using OxCal calibration software (Bronk Ramsey 2009) based on Bayesian principles (Bayes 1763). The modeled distribution of the data is given with calculated agreement indexes. The agreement between the posterior distribution of the data and the prior distribution follows the convention of $\mathrm{OxCal} v 4.1$ where $60 \%$ is taken as the threshold for acceptance for individual and overall agreement indices (Bronk Ramsey 2009).

At sites where samples from more than 1 sequential deposit exist, dates were grouped into distinct archaeological phases, such that in a known sequence of archaeological events, the lowest layer is reasonably assumed to have formed before any and all overlying layers. For the Early Bronze Agebased nomenclature, the transitions of EB IA/IB, EB I/II, EB II/III, and EB III/IV-IBA are calculated. As noted above, our models were performed using chronological classifications as given by the excavators. Additional models were run according to refinements made by individual authors of this paper.

In the Early Bronze Age, production rates of ${ }^{14} \mathrm{C}$ fluctuated, resulting in several plateaus and wiggles in the calibration curve (Reimer et al. 2004, 2009). These plateaus and wiggles, combined with normal laboratory error, affect precision of ${ }^{14} \mathrm{C}$ dates, sometimes resulting in calibrated ranges of a few hundreds of years. Altogether, modeling enables a narrowing down of what are sometimes quite large ranges of dates, and produces relatively precise dates for associated archaeological deposits.

Each site was analyzed individually to allow for overlapping and contemporaneousness between sites, since it was taken as a logical rule that within each site internal stratigraphy would be consistent, but separate sites might have similar cultures prevailing over varied lengths of time (due to their particular settlement trajectories).

In each model, samples from the same subperiod are ordered as "phases," while in each phase samples are ordered from oldest to youngest. This does not indicate that samples were necessarily found in that order in archaeological layers. A presupposition behind the term "phase" is that the samples do not have a known order within a phase, while dates are distributed evenly between boundaries. The boundaries used in the models in most instances are "contiguous," meaning that a boundary is calculated in such a way that each phase begins where the previous phase ended.

In this study, we are only interested in major transitions between periods and phases. In our view, the "contiguous" boundary best describes the situation of single archaeological sites considered, where each phase is supposed to follow one another. When the sequence is not contiguous (as in the case of Beth Yerah where there are no EB IB dates in the sequence), a "sequential" boundary is used. This boundary will give an "end" range for the earlier phase and a "begin" range for the following phase, leaving a possible gap in between. Two basic models were built at each site: one of all samples and the other of seeds only. Each model was analyzed separately and outliers were removed.

\section{Definition, Identification, and Removal of Archaeological \& Analytical Outliers from Sequences}

The identification of outliers is an important outcome of Bayesian modeling. Agreement indices provide a warning if a certain date cannot be statistically fitted into a phase from which it purports to originate. The reason a date is defined as an outlier needs to be specified before it is removed from a sequence. As a general rule, any sample with an agreement of below $60 \%$ within a model is considered an outlier and removed. Elimination of a date from a model is not based only on an agreement index. In fact, considerations based on types of samples, archaeological contexts, and historical information might support removal of samples despite their having sufficiently high agreement 
indexes. Often, several outliers appear and they are removed one by one; the program being run anew after each removal. Then, archaeological contexts of samples that appear as outliers in the model are re-examined for possible reasons for their anomalous dates.

The following guidelines were applied in this study for identifying and removing outliers for transition modeling:

1. Any single date that had less than $60 \%$ agreement was considered an outlier. This did not yet necessitate the removal of the ${ }^{14} \mathrm{C}$ date.

2. Samples within phases were ordered from oldest to youngest. The first sample in the first phase and the last sample in the last phase are sometimes considered as outliers by the program. They were not removed despite their low agreement.

3. Outliers were removed one by one in order to verify changes in agreement indices. Note that in some cases a date with less than $60 \%$ agreement in the first analysis rises above or approaches the $60 \%$ agreement limit when another date is omitted, thus making it possible to leave the sample in the final model. Sometimes, samples with 57-60\% agreement were left in the models.

4. Seeds were preferred over charcoal samples, in order to avoid the old-wood effect. Thus, seed samples, even if they appeared as outliers, were preferably left in if "too old" charcoal samples could be removed instead.

Note that the "ending" and "beginning" dates are not considered as real dates, since the program calculates the shortest duration for the phases and that might not accurately depict actual durations. We only show figures of the final model. Results of some of the models that were built while attempting to reach the final model are given in Table 2. Outliers are shown in the plot but have been removed from the model.

\section{Modeling Results of Sites with at Least 1 Transition}

The results of the various models with the best estimated transitions between contiguous and sequential phases (as calculated using OxCal v 4.1) are given in Table 2. Short-lived samples are marked with asterisks. In the following section, various models are described and their results given. All boundary dates are given for $\pm 1 \sigma$ probability distribution ranges. The $\pm 2 \sigma$ probability distribution ranges can be seen in Table 2. The modeled boundaries are summarized in Figure 11. All dates are given in calibrated years $\mathrm{BC}$.

\section{Tell Abu Al-Kharaz}

Tell Abu Al-Kharaz has 14 dates assigned to the "Final EB IB" (6 samples) and EB II (8 samples) (Figure 3). All the samples are considered to originate from secure contexts (Stadler and Fischer 2008). When the model is run with all the samples, 2 samples (OxA-4332, OxA-4329) are outliers.

The model where these outliers are excluded indicates that the transition from "Final EB IB" to EB II at Tell Abu al-Kharaz occurred sometime between 3070 and 2970 BC. If the model is based only on short-lived samples ( 2 for Final EB IB and 2 for EB II), then the transition is calculated between 3000 and $2910 \mathrm{BC}$.

According to the modeling results, the old-wood effect at Tell Abu al-Kharaz is possibly $\sim 50 \mathrm{yr}$, an estimation enhanced by one of the seed samples found in a jar. Thus, we suggest that the EB IB-II transition date at Tell Abu al-Kharaz should be located between 3000 and $2910 \mathrm{BC}$. 


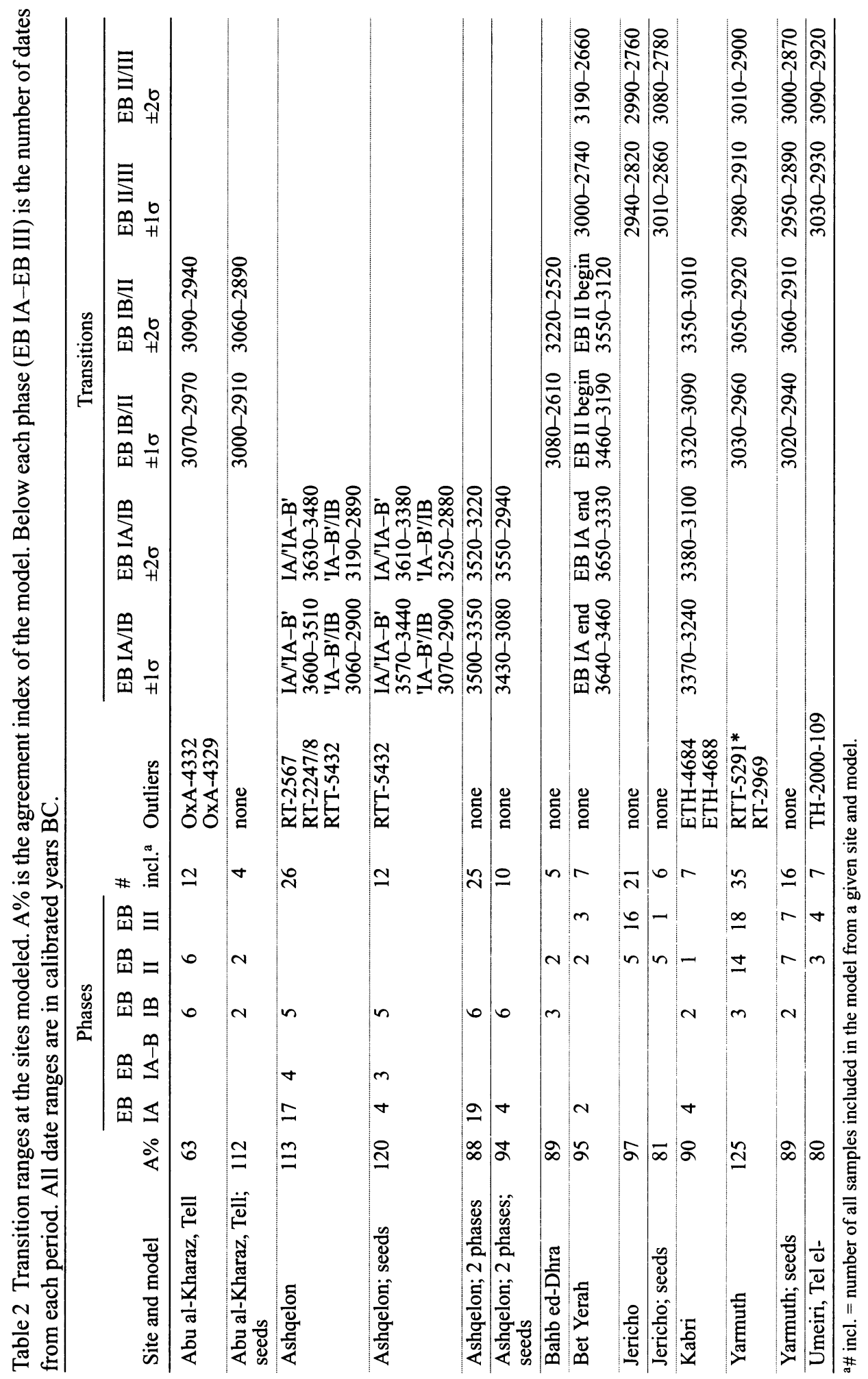




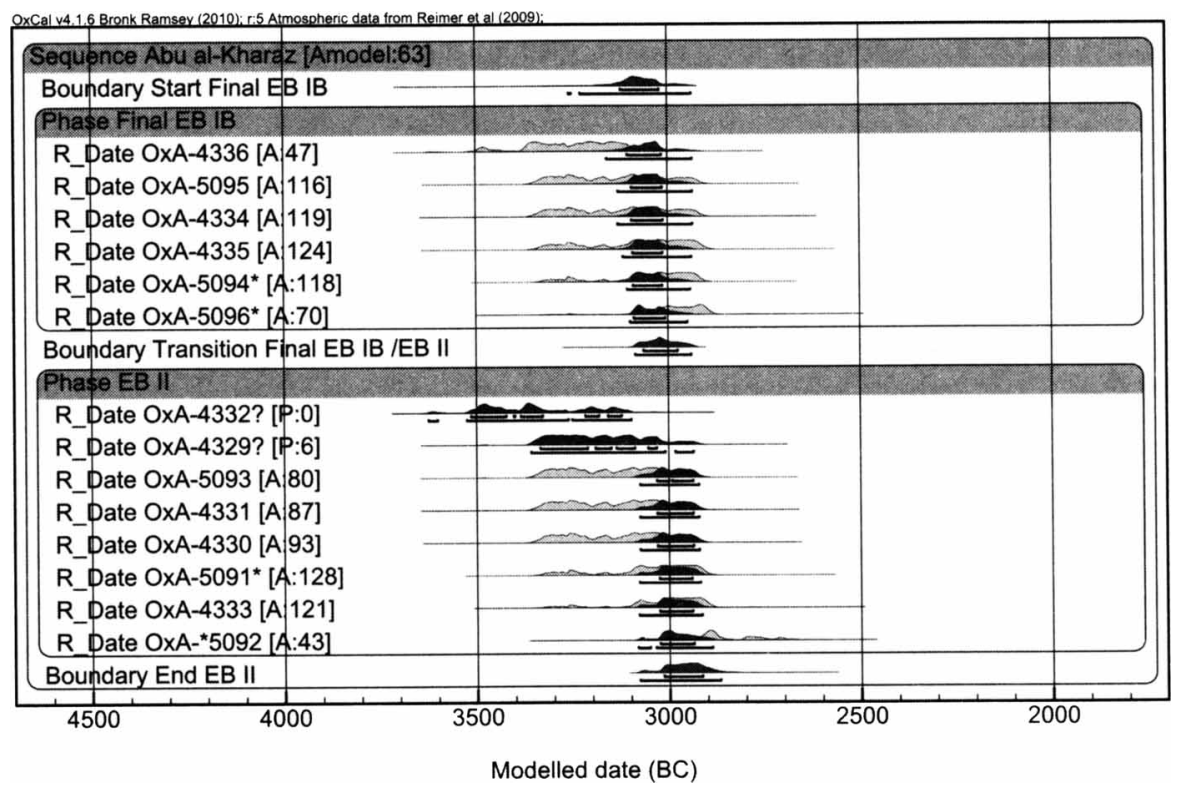

Figure 3 Modeling result of ${ }^{14} \mathrm{C}$ dates from Tell Abu al-Kharaz

\section{Ashqelon}

Twenty-nine dates originate from a cluster of sites at Ashqelon (see Table 1). These are from different phases/subperiods of EB I, some of which are not in stratigraphic relation to each other (i.e. they are from separate, though adjacent, sites). There are different interpretations regarding the subdivision of the phases discernible at different locales within the cluster (Braun 1996; Golani 2004; Golani and Segal 2002; Yekutieli 2006 and references in Table 1).

For purposes of this modeling, we have simplified the chronocultural divisions and maintained the excavators' designations, although at least one of the authors is in strong disagreement with some of the identifications suggested (Golani 2004; Golani and Nagar 2011; contra Braun 2001; Braun and Gophna 2004). Nineteen dates are indicated for what is purported to be EB IA, while for EB IB there are 6 (Figure 4). An additional 4 dates originate from a context described as a transitional phase between EB IA and IB (henceforth "phase EB IA-IB"). In this model with 3 phases, 3 samples appear as outliers (RT-2567, RT-2247/8, RTT-5432). Thus, according to this model the transitions occurred for EB IA to EB IA-IB between 3600 and 3510 BC and for EB IA-B to EB IB between 3060 and $2900 \mathrm{BC}$. When the same model is run only with seed samples, 1 sample is an outlier (RTT-5432), and the transition EB IA to EB IA-B occurs between 3570-3440 BC and for EB IA-B to EB IB between 3070-2900 BC.

If the period EB IA-IB is omitted, there are no outliers in the model. The transition between EB IA to EB IB becomes larger and is between $3500-3350 \mathrm{BC}$. When only seed samples are used for the EB IA to EB IB, the transition becomes even wider, giving a range between $3430-3080 \mathrm{BC}$. This is later than when the model uses charcoal samples, pointing to a possibility of some old-wood effect.

The very wide time range of $\sim 300 \mathrm{yr}$ calculated for the EB IA to EB IB transition when the EB IAIB phase is omitted, suggests an interestingly long duration for this phase, which to one of the authors (E Braun) seems untenable considering what is understood of the somewhat scant archaeo- 


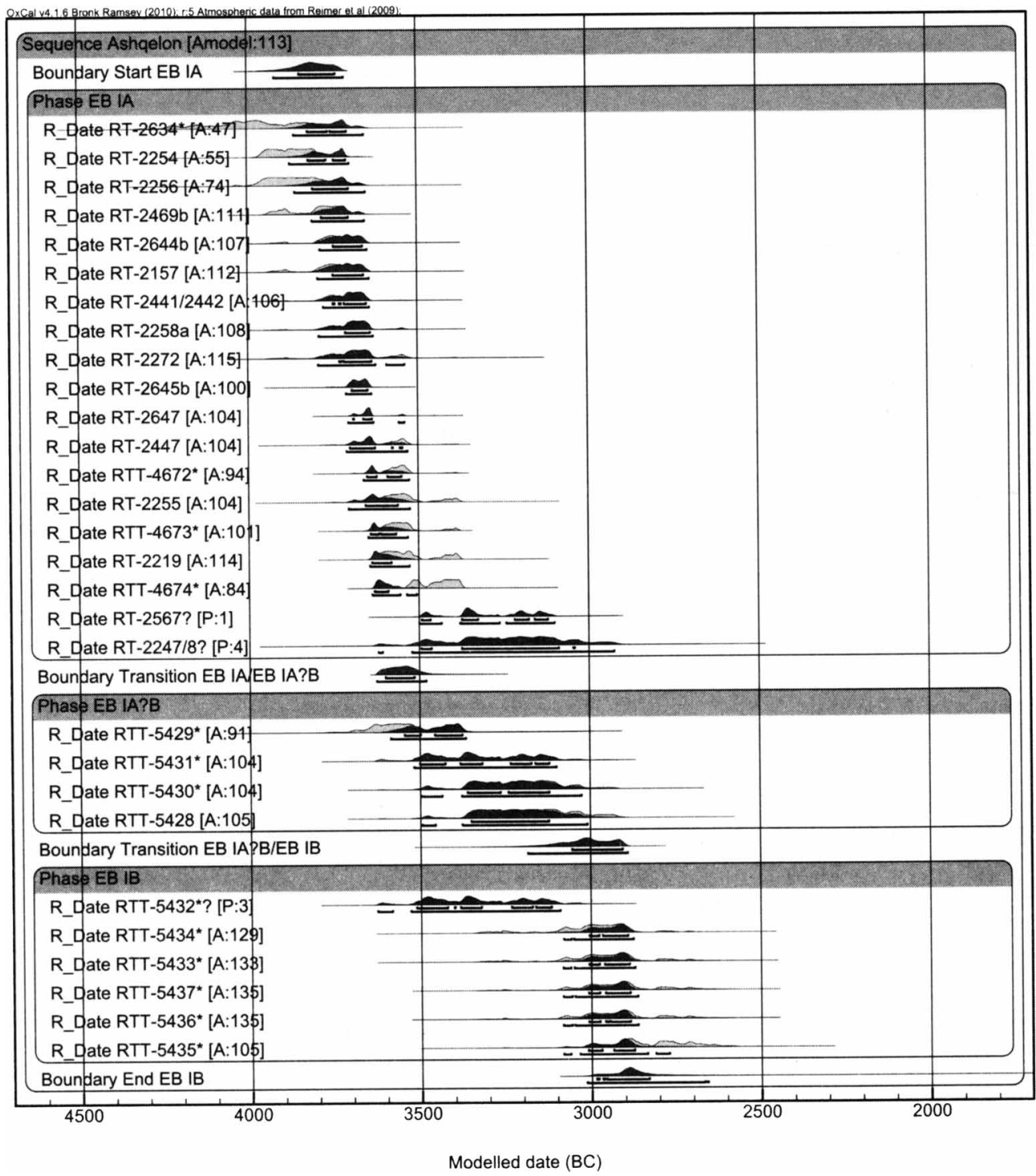

Figure 4 Modeling result of ${ }^{14} \mathrm{C}$ dates from Ashqelon

logical record at the Ashqelon sites, which Golani and Nagar (2011) suggest covers the entire EB I period. Braun suggests the results are skewed by data incorrectly attributed to EB IA. Currently, all the EB IA date ranges (except RT-2567 and -2247/8, which are considered outliers in the modeling) end before $3380 \mathrm{BC}$, and most of them even before $3500 \mathrm{BC}$, suggesting that at Ashqelon, EB IA dates to the second quarter of the 4th millennium. The EB IB date ranges, with 1 exception, do not start before $3100 \mathrm{BC}$. This might suggest the dates were derived from the latest EB IB phase. Additionally, the calibration plateau between about 3400-3100 BC makes the beginning of EB IB difficult to pinpoint. 


\section{Bab edh-Dhra}

The site of Bab edh-Dhra has had 30 dates measured and published since the 1970 s. If a model is run with all 21 dates assigned to clear archaeological phases by the excavators, there are 5 phases corresponding, respectively, to EB IA, EB IB, EB II, EB III, and EB IV (Figure 5). The outcome of the model is highly improbable and 9 samples turn out to be obvious outliers (SI-3310B, $-2871,-2877$, $-2502,-2876,-4134,-4135,-2869,-2870)$. The SI (Smithsonian Institution) dates appear too old for the model. Whether this is due to problematic contexts in the excavation or some mistakes made in the lab is uncertain. Since the context is considered partly mixed and the dates exhibit large spans of time, it was decided to include only the more recent dates in the final model, even though only the EB IB and EB II boundary can be examined. When only the 2003 dates are used, no outliers exist. In this model, the transition from EB IB to EB II occurred sometime between 3080-2610 BC. This long transition is probably due to the very few dates in the model and whether the samples came from the end or beginning of the dated phase.

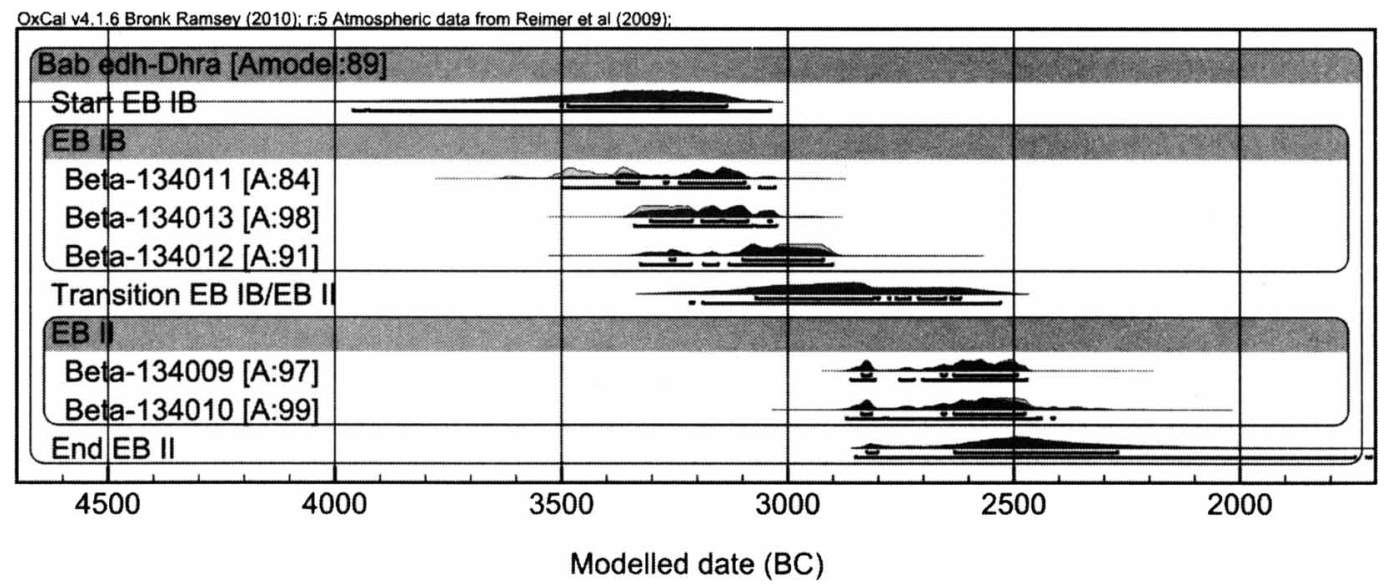

Figure 5 Modeling result of ${ }^{14} \mathrm{C}$ dates from Bab edh-Dhra

\section{Bet Yerah}

At the site of Tel Bet Yerah, 7 dates are available for modeling from recent excavations: EB IA (2), EB II (2), and EB III (3). Using a "sequential" boundary between EB IA and EB II, which allows for a gap between the two, no outliers exist in the model (Figure 6). The end of EB IA and the beginning of EB II occur sometime between 3640 and 3190 BC. The 2 EB IA dates probably originate from the very beginning of the period, and a large gap in dated occupation layers exists until the next period dated, EB II. Thus, the EB IA end boundary is highly artificial, offering only rough estimations of the actual dates. The EB II-EB III transition, between $3000-2740 \mathrm{BC}$, is very broad. This can be explained by either a gap in the ${ }^{14} \mathrm{C}$ samples from either late EB II or early EB III, or a substantial old-wood effect for the EB II samples. This cannot be verified since only a limited number of dates are currently available for modeling from the site.

\section{Jericho}

Twenty-eight dates from Jericho have been measured. In the model, the samples originating from tombs are excluded, leaving 21 dates available for modeling: 5 from EB II and 16 from EB III contexts. No outliers exist in the model. The EB II/EB III transition occurs between 2940 and 2820 BC. 


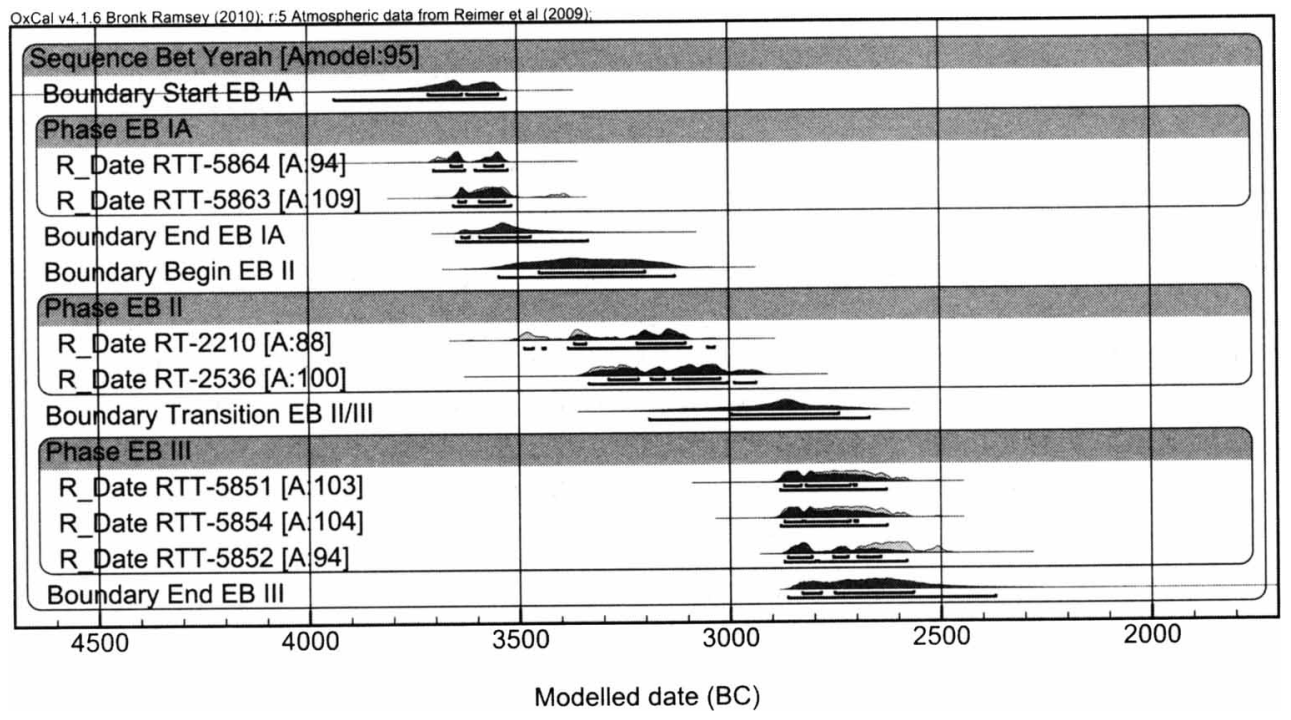

Figure 6 Modeling result of ${ }^{14} \mathrm{C}$ dates from Bet Yerah

When only seeds are used in the model, the transition occurs slightly earlier, between 3010 and 2860 $\mathrm{BC}$ (Figure 7).

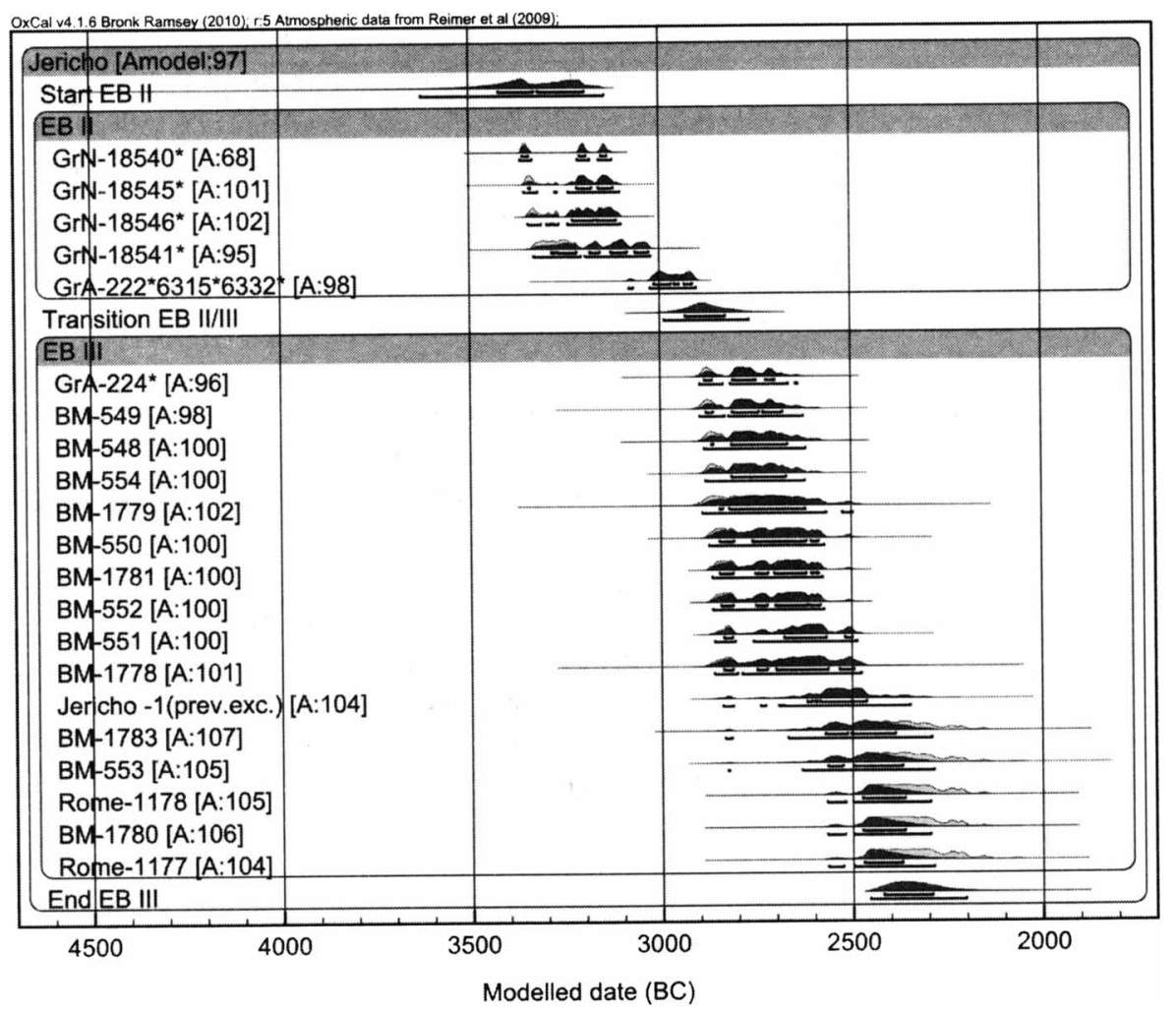

Figure 7 Modeling result of ${ }^{14} \mathrm{C}$ dates from Jericho 


\section{Tel Kabri}

At Tel Kabri, 9 samples are available for modeling, originating from EB IA (6), EB IB (2), and EB II (1) contexts (additional information on the sample contexts was kindly provided by Naama Scheftelowitz). In the model, 2 samples are removed as outliers (ETH-4684, -4688; Figure 8). The transitions occurred from EB IA to IB between 3370-3240 BC and from EB IB to EB II between 33203100 BC. All samples consist of charcoal, which could suggest some old-wood effect.

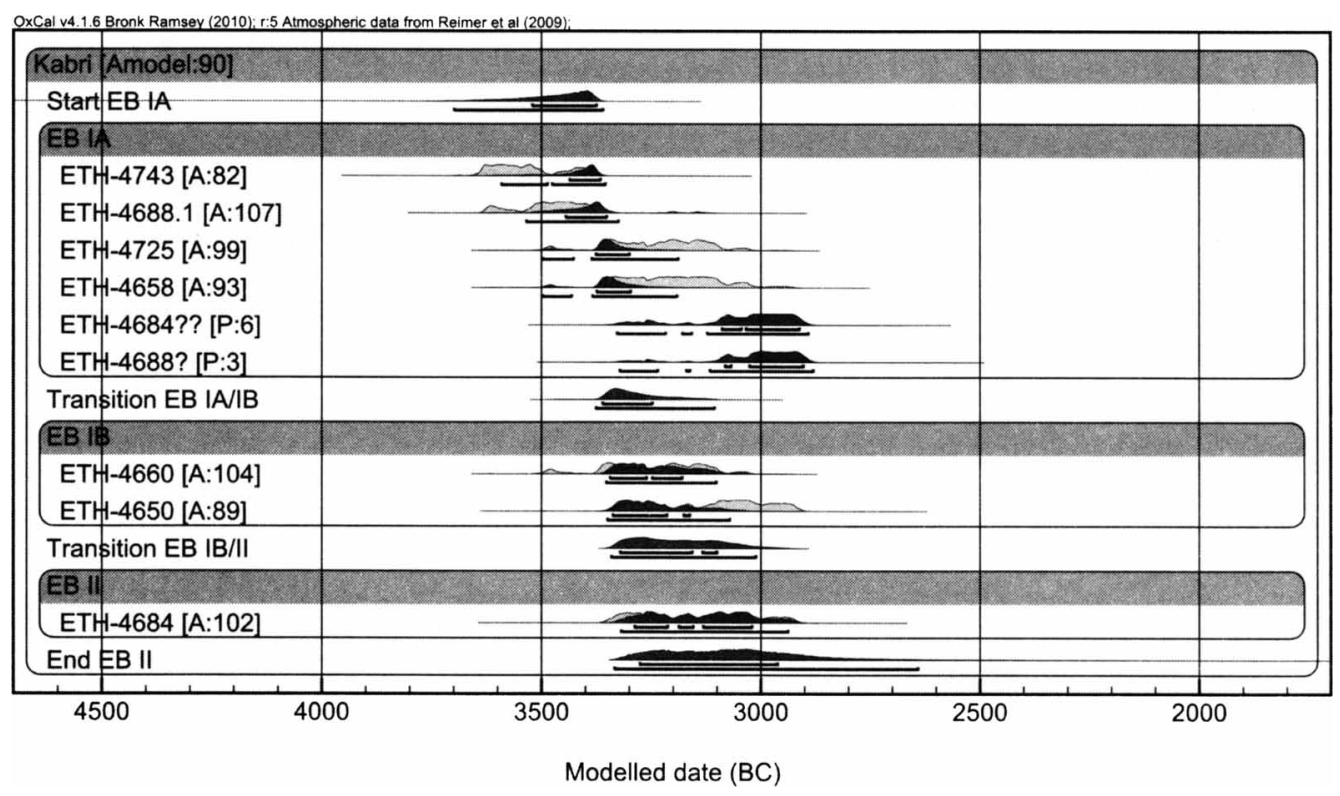

Figure 8 Modeling result of ${ }^{14} \mathrm{C}$ dates from Tel Kabri

\section{Tell el-Umeiri}

At Tell el-Umeiri, 9 dates are available for modeling (Figure 9). Sample TH-2000-113 is an obvious outlier and is thus removed from the model. When the model is run with 8 samples, from EB II (3) and EB III (5), sample TH-2000-109 appears as an outlier. When it is removed, the transition between EB II and EB III occurs between 3030-2930 BC. All the samples consist of charcoal.

\section{Yarmuth}

At Tel Yarmuth, 37 samples are available for modeling: 3 from Final EB IB, 15 from EB II, and 19 from EB III (Figure 10). In the model, we removed samples RTT-5291 and RT-2969 as outliers. Sample RT-2969 might suffer from an old-wood effect. Sample RTT-5291 remains below $60 \%$ agreement, even if the 3 earliest charcoal samples of the EB III phase are removed. Thus, even though it is a short-lived sample, it is removed as an outlier. Based on stratigraphically more detailed models, sample RTT-5286 also becomes an outlier, and sample RT-2965 is also a clear outlier (Regev et al., these proceedings). In this model, the transition from Final EB IB to EB II occurs between 3030 and $2960 \mathrm{BC}$. The EB II to EB III occurs between 2980 and $2910 \mathrm{BC}$. If the model is made only with seeds, no samples appear as outliers, and the transitions are about $20 \mathrm{yr}$ later. 


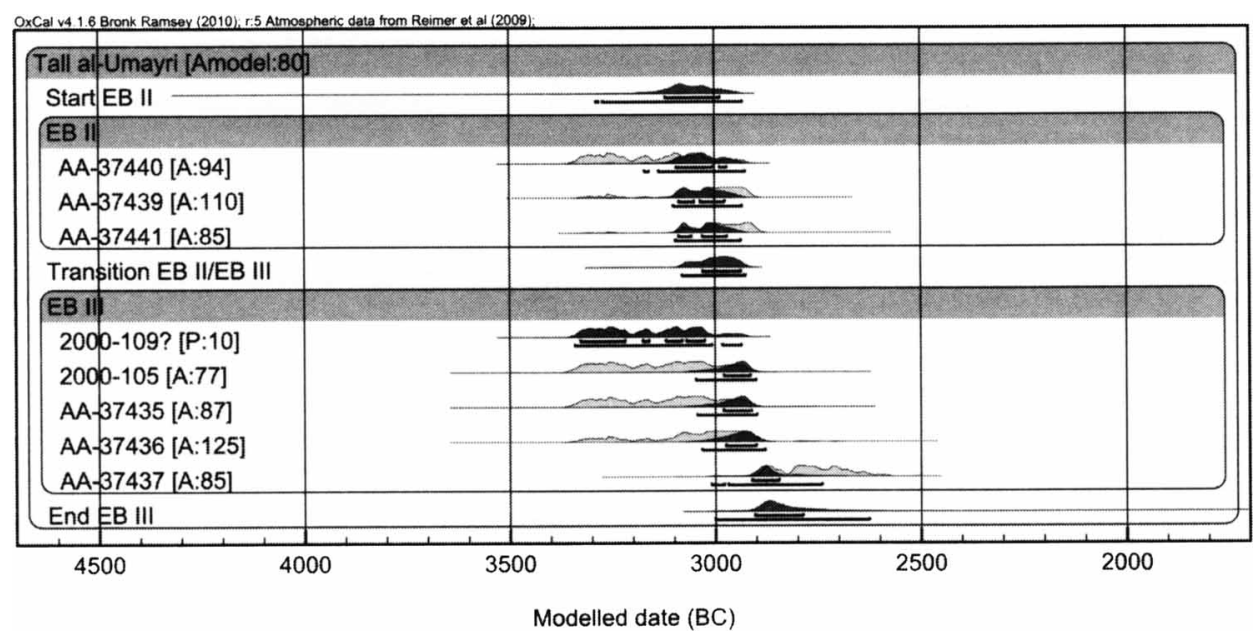

Figure 9 Modeling result of ${ }^{14} \mathrm{C}$ dates from Tell el-Umeiri

\section{Multiplot and Overview}

As a result of modeling, 11 additional samples were removed, leaving 189 samples to be used for obtaining the final results. These can be seen in the colored plot (Figure 11). As the modeled transitions are timespans, they are represented in the chart by diagonally divided squares depicting end and beginning dates for the boundary. The results are based on the dates after selection according to contexts (where a single period was dated). Clear ${ }^{14} \mathrm{C}$ outliers and outliers identified by modeling were removed as well. Circles above and below dated periods indicate that archaeological contexts from later or earlier periods have been reported from a particular site, but not ${ }^{14} \mathrm{C}$ dated. This additional information is relevant in order to identify possible intrusive or residual samples.

\section{DISCUSSION}

\section{Transitions}

Given the statistical nature of the modeling and the incompleteness of the archaeological record at many sites, and in order to simplify the discussion, the ranges determined for the different periods have been rounded to the nearest $50 \mathrm{yr}$. The results are summarized in Figure 11. The transitions in the figure are not rounded and are according to the text in the Results section.

The shape of the calibration curve in the 4th and 3rd millennia is an aspect that should be kept in mind with modeled transitions, since the accuracy of the dates is greatly affected by it. Two significant plateaus exist in the timespan addressed in this paper: one between 3350 and $2910 \mathrm{BC}$; the other between 2850 and $2500 \mathrm{BC}$. However, the deep slope between 2910 and $2880 \mathrm{BC}$ clearly divides the dates and enables very precise dating within that timespan.

Transitions are addressed in the following manner: First, the results of modeled sites are discussed, then the non-modeled dates from single phase sites and the non-modeled start and end of periods in modeled sites.

The beginning and the end of the EBA cannot be determined with this set of dates since we did not include Chalcolithic and Middle Bronze ${ }^{14} \mathrm{C}$ dates. Using the date ranges at hand, the earliest dated EB IA levels are at the sites of Ashqelon and Beth Yerah, where the dates cluster around $3700 \mathrm{BC}$, 


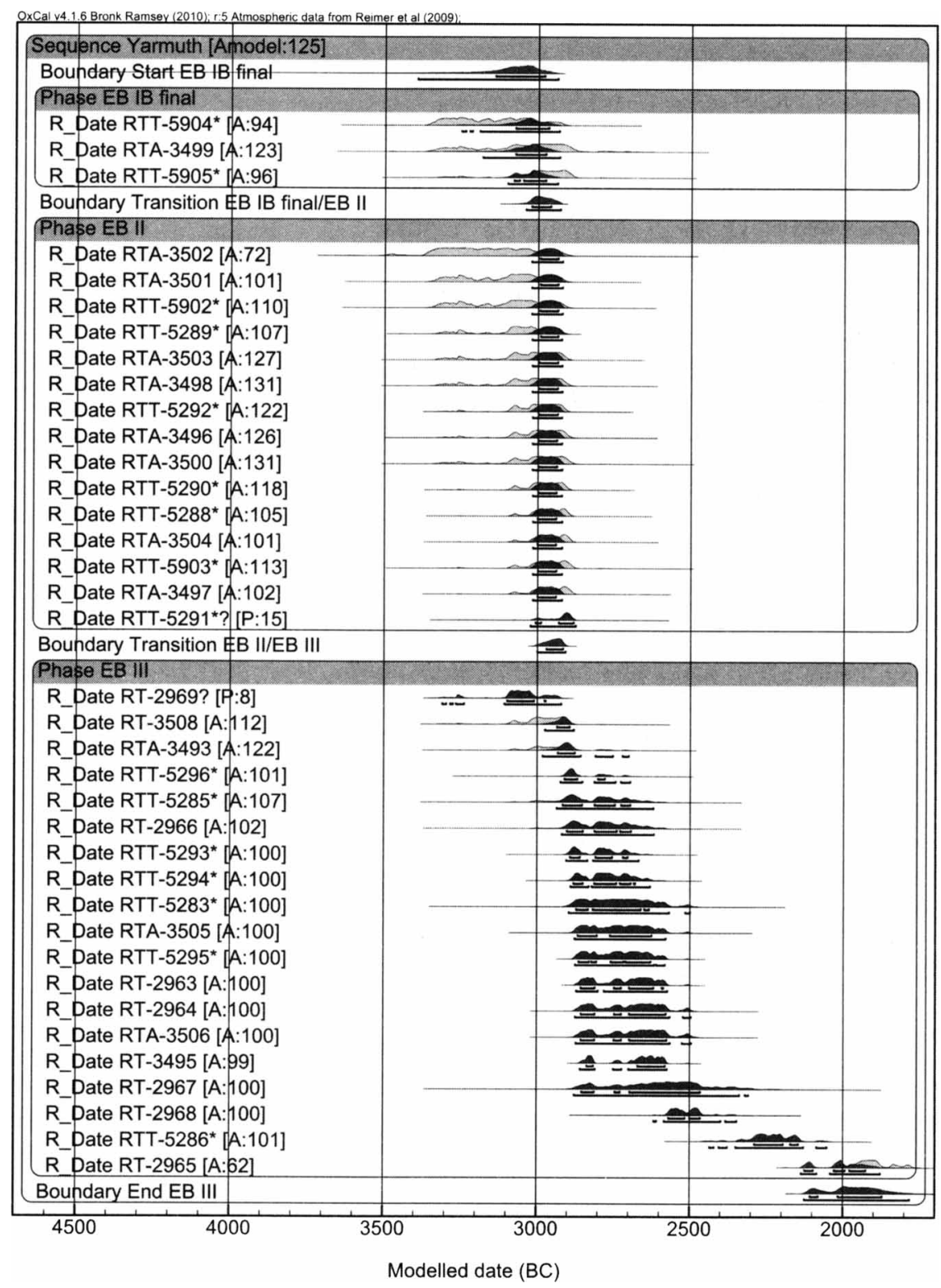

Figure 10 Modeling result of ${ }^{14} \mathrm{C}$ dates from Tel Yarmuth

or perhaps even earlier. Four additional sites (Modi' in, Taur Ikhbeineh, Sataf, and Kabri) where ${ }^{14} \mathrm{C}$ dates were obtained show some variations for the dated samples of EB IA, but they are generally younger and date closer to $3500 \mathrm{BC}$ or even later. It should be noted that the site of Tell esh-Shuna also provided early dates for the beginning EB IA phase, with the calibrated ranges starting around 3900 BC. The dates for EB IV suggest it ended $\sim 1950$ BC. 


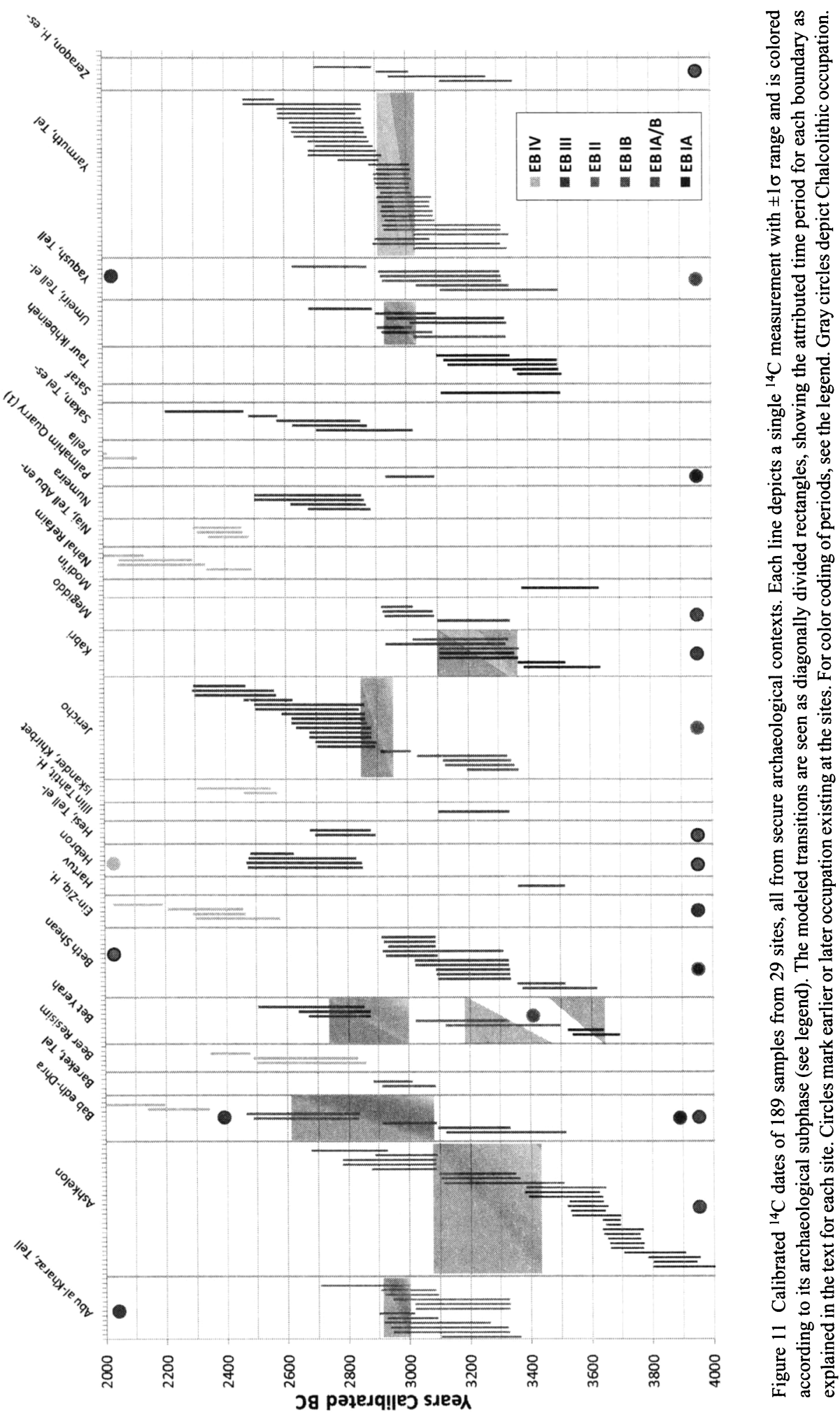




\section{The EB IA-EB IB Transition}

Modeled: The EB IA to IB transition can be modeled at 2 sites, Ashqelon and Kabri $(200 \mathrm{~km}$ north of Ashqelon). At Ashqelon, the transition falls between 3450-3100 BC, while at Kabri, according to the model, it took place around 3350-3250 BC. This difference could be due to the distance between the 2 sites, gaps in the ${ }^{14} \mathrm{C}$ data caused by lack of dates from the end and beginning of the consecutive phases, or it may be the result of differing interpretations of what constitutes EB IA. It should be noted that at Tell esh-Shuna the modeled transition is $3500-3350 \mathrm{BC}$ (the model consists of 8 samples from EB IA and 6 samples from EB IB, with no outliers). At Bet Yerah, the EB IA to IB transition cannot be determined, since no EB IB dates exist. Currently, the ${ }^{14} \mathrm{C}$ data, limited as they are for reasons discussed above, do not allow pinpointing the transition clearly, and some variation exists between the various sites, probably due to the different parts of the phases dated.

Non-modeled: There seems to be some overlapping in date ranges between the EB IA and EB IB of different sites. It should be noted that none of the EB IA ranges continue after $3100 \mathrm{BC}$, and most of the date ranges end much earlier, before $3400 \mathrm{BC}$.

\section{The EB IB-EB /| Transition}

A long history of terminological confusion surrounding the EB IB-EB II transition (Amiran 1969; Wright 1971) makes it likely that different opinions on the cultural definition of these periods has affected the models of the transition between them.

Modeled: The EB IB to EB II transition was modeled at 4 sites. At Yarmuth and Tel Abu-Kharaz, the transition occurred $\sim 3000 \mathrm{BC}$. Using currently available data from Kabri, the transition would seem to have occurred earlier, while at Bab edh-Dhra the EB II dates are later, resulting in a wide EB IB to EB II transition, ending $\sim 2600 \mathrm{BC}$. The indicated transitions with most dates are at Yarmuth and Abu al-Kharaz; their contexts are well defined and correspond to "Final EB IB." A range of 3050 $2950 \mathrm{BC}$ for these 2 sites is securely based. This result is similar to that suggested by the sequence of dates from Pella (Bourke et al. 2009). The other 2 sites (Kabri and Bab edh-Dhra) need more dates to obtain a better understanding of the transitions, and whether they occurred simultaneously.

Non-modeled data: Even more than in the previous periods, there is an overlap between the EB IB/ "Final EB IB" and the EB II dates. If we were to base this transition on non-modeled sites, it would be fairly difficult to determine when the transition occurred, since the date ranges of both periods end simultaneously around $2900 \mathrm{BC}$. In fact, the EB IB and the EB II date ranges end at the same time in most of the sites.

The EB IB to EB II transition is conventionally dated to the beginning of the 1st Dynasty, at about 3000 BC (Braun 2011a). In our chronological scheme, it seems to stay generally within the conventional realm, but did not necessarily occur at one time at different sites. The transitions that can be most securely established in our study are at Tel Yarmuth and Tel Abu Kharaz, where the boundary falls between 3050 and $2950 \mathrm{BC}$. Based on available data, we cannot exclude the possibility of some coexistence between the cultures termed, by various scholars, EB IB and EB II. This, however, may actually reflect the terminological confusion surrounding the EB IB-EB II transition.

\section{The EB II-EB III Transition}

Modeled: The transition between the EB II and EB III periods is an especially interesting one. It is based on 4 modeled sites. At Tel Yarmuth and Tell el-Umeiri, the transition falls between 3000 and 2900 BC. At Jericho, data suggest the transition occurred slightly later, in the 2950-2850 BC range, 
while at Bet Yerah, probably due to the small amount of dates, the transition has a larger range, from between 3000-2750 BC. As most dates come from Tel Yarmuth and Tell el-Umeiri, measurements of the duration of the transition are likely to be most precise. Thus, the suggested EB II/EB III transition seems to have occurred $\sim 2900 \mathrm{BC}$.

Non-modeled data: A clear pattern can be discerned in the dates of EB II and EB III. All of the EB II date ranges from west of the Jordan River, except for 1 date from Tel Yaqush, end 2900 BC, whereas EB III dates commence directly afterwards, with only a few dates being slightly older. Some of the EB II date ranges from sites on the east side of the Jordan River continue later (Bab edhDhra, Abu al-Kharaz, and Tell es-Sa'idiyeh).

The EB II to EB III transition is probably the most obvious and securely documented change in the ${ }^{14} \mathrm{C}$-based chronology. Conventionally, it is dated $\sim 2700-2600 \mathrm{BC}$ and correlated with the beginning of the 3rd Dynasty in Egypt (Mazar 1992; de Miroschedji 2000), although an earlier date of $\sim 2800 \mathrm{BC}$ has been suggested, on various grounds (Philip and Millard 2000; Greenberg 2002). However, there is no archaeological basis for this correlation. This exercise in dating may vary slightly depending on which Egyptian chronology is used (e.g. Kitchen 1991; Shaw 2000; Hornung et al. 2006).

Our ${ }^{14} \mathrm{C}$-based evaluation suggests that the transition from EB II to EB III could have been underway as early as $2900 \mathrm{BC}$, which suggests a shift of $\sim 200 \mathrm{yr}$ earlier than conventional chronologies indicate. When this shift is taken into account together with the EB IB to EB II transition, it suggests that only a very short duration of 100 to $200 \mathrm{yr}$ is left for the EB II period, reducing its span by 200$300 \mathrm{yr}$. It should be noted that, from 2920 until $2850 \mathrm{BC}$, a strong slope exists in the calibration curve, equivalent to $\sim 4350-4200$ uncalibrated BP. As the EB II-III transition falls within this slope at $\sim 2900 \mathrm{BC}$, the precision of the transition date is enhanced.

\section{The EB III-EB IV/IBA Transition}

Modeled: No modeling was possible for the fourth transition, since no sites currently exist where both EB III and EB IV/IBA have been ${ }^{14} \mathrm{C}$ dated.

Non-modeled: Large variations exist within the available EB IV ${ }^{14} \mathrm{C}$ dates, which suggest the period potentially began much earlier than previously thought. The last urbanized EBA period, EB III, offers data from 9 sites, while for the non-urban EB IV, 7 sites were dated. At all EB III sites, with the exception of 5 samples from Jericho, 1 sample from Tell es-Sakkan, and 2 samples from Tel Yarmuth, which are very probably outliers (Regev et al., these proceedings), the latest part of the date range lies between 2500 and $2450 \mathrm{BC}$. An earlier date for the end of EB III is also possible since the calibration curve gives quite a wide range of possibilities. The following EB IV date ranges have large variations: the earliest (Beer Resisim) beginning as early as $2850 \mathrm{BC}$ and the very latest ending after $2000 \mathrm{BC}$. For the majority of the sites, the beginning of EB IV/IBA can be placed around $2500 \mathrm{BC}$, and neatly bridge the period between EB III and EB IV. If this were not the case, a gap in human activity in the southern Levant might be inferred between these 2 periods, since the EB III dates end at that time.

The end of the EB III cultural horizon is traditionally seen as contemporaneous with the reign of Pepi I (de Miroschedji 2012), variously dated by Egyptologists to 2321-2287 BC (Shaw 2000) or 2289-2255 BC (Baines and Malek 1980), and recently by ${ }^{14} \mathrm{C}$ to $2399-2310 \mathrm{BC}(1 \sigma)$ or 2389-2349 $\mathrm{BC}(2 \sigma)$ (Bronk Ramsey et al. 2010). The shift of several centuries in the beginning dates for the EB III period in this scenario could stretch the EB III to a lengthy $600 \mathrm{yr}$. However, according to the ${ }^{14} \mathrm{C}$ data, the latest EB III dates do not reach so late in time. While it could be explained as the result 
of a gap in the ${ }^{14} \mathrm{C}$ record due to the absence of samples from the latest EB III deposits, the EB IV dates here actually suggest that the latter period began earlier than previously thought, which implies either an earlier transition or an overlap with EB III.

Currently, many dates exist for the EB III period (derived from 56 samples of good contexts). Of those dates, only 4 ( 3 from Jericho and 1 from Tell es-Sakan) are later than 2450/2500 BC. Hence, the data suggest that many EB III sites were abandoned about or before $2500 \mathrm{BC}$, which suggests a shift upward of $\sim 200 \mathrm{yr}$ from the conventional date of $2300 \mathrm{BC}$ suggested by some scholars (e.g. Mazar 1992; de Miroschedji 2000). It is important to obtain more dates from the latest EB III layers at various sites in order to determine whether the end of the EB III did occur simultaneously throughout the southern Levant or whether it ended at different times in different places. Cultural aspects of these changes in the periodization of the EBA are obviously crucial in understanding causes for the decline of urbanized society.

\section{Further Test}

A model using all the samples from good contexts included in Figure 11 was built. The 5 samples (Ashqelon and Hartuv) from "transitional" EB IA/IB were not included to avoid additional phasing, leaving 184 samples for the model. Using all 184 samples, the only model to reach convergence is one where the phases were allowed to overlap (i.e. being contemporaneous), having "overlapping boundaries." In the model with contiguous boundaries, 21 samples are removed as outliers (RT2154*, RT-2324, Beta-134011, RTT-5435*, RT-2210, OxA-2813, GrN-18540*, GrN-18545*, GrN18546*, OxA-2814, GrN-18541*, OxA-*5092, OxA-2810, Beta-134009, Beta-134010, Hd-19610, TH-2000-105(1), TH-2000-106(2), Hd-19625, BM-1780, Beta-163588) and still some additional samples remain slightly below $60 \%$ agreement. Agreement of the model is $87 \%$. The transitions obtained are

EB IA-IB: $3150-3070 \mathrm{BC}$;

EB IB-II: 3030-2940 BC;

EB II-EB III: 2950-2910 BC;

EB III-IV/IBA: 2570-2520 BC.

Taking the same data (184 dates) and modeling them by using only 2 adjacent periods, the results are slightly different. Also, in this case many outliers need to be removed:

EB IA-IB: 3330-3150 BC. The outliers removed for EB IB are RT-2154* and RT-2324* (A\% = 99). In this transition, it is possible to change the results by choosing whether to remove outliers from EB IA or EB IB phase. The removal of the 2 latest EB IA samples will cause the boundary to become over $100 \mathrm{yr}$ older.

EB IB-II: 3080-3040 BC. In this case, many outliers would need to be removed to reach any agreement. This is because the dates of EB IB and EB II are practically the same. Therefore, depending which outliers are removed, the transition changes substantially. Using the $\mathrm{OxCal}$ agreement values $(\mathrm{A} \%)$ on dates, the identified outliers for EBI are RTT-3902*, GrA-222*6315*6332*, OxA-5096*, RTT-5436*, RTT-5437*, RTT-5435*; for EB II: RT-2210, OxA-2813, GrN-18540* (A\%=31).

EB II-III: 2940-2910 BC. The outliers removed for EB II are OxA-*5092, OxA-2810, Beta-134009, and Beta-134010; for EB III: Hd-19610, 2000-105, TH-AA-37435, Hd-19625 (A\% = 83). This boundary is quite straightforward, with clear outliers at the edges.

EB III-IV: 2570-2520 BC. The outliers removed for EBIII are BM-1780, Beta-163588, and BM-553 $(\mathrm{A} \%=78)$. The boundary can be lowered to $2500 \mathrm{BC}$ by choosing the oldest $\mathrm{EB}$ IV dates as outliers, but generally the boundary is clear. 
The method used throughout our study was to model individual sites separately. When dates from different sites are combined, the results can vary depending from the outliers eliminated. The differences suggest either a degree of overlap between cultural horizons, inaccurate or wrong cultural association to contexts, or both. With the current state of research, the methodology suggested is to model sites individually.

\section{CONCLUSION}

\section{Archaeological Implications}

The ${ }^{14} \mathrm{C}$ dates and modeling presented above demonstrate that the traditional dating of the divisions of the southern Levantine Early Bronze Age should be revised. Taking into account that transitions from one EB subperiod to another did not necessarily occur simultaneously at all sites, the transitions between subperiods should be considered as ranges, within which cultural changes interpreted as "transitions" occurred. This would question the synchronization between sites.

Based on the context and ${ }^{14} \mathrm{C}$ data after applying quality criteria for their inclusion in the model, we suggest the following chronological scenario: The EB IA to EB IB transition did not necessarily take place within a very short time at all sites. The dates for this transition, where it can be modeled, span anywhere between $3450-3100 \mathrm{BC}$ at the different sites. The relatively large transition could be due to overlapping of periods/subperiods defined by scholars, which clouds the issue and makes the data unreliable as to what they represent. The following EB IB and "final EB IB" to EB II transitions are calculated at different sites with large differences, with dates between 3200-2900 BC. The next 2 transitions appear to have taken place more in sync throughout the region. A date around $2900 \mathrm{BC}$ seems to be firmly based for the EB II to EB III transition, which is at least $200 \mathrm{yr}$ earlier than the traditionally accepted dates. Similarly, the EB III cultural horizon, which appears not to have continued after $\sim 2450 \mathrm{BC}$, could possibly have come to an end at some sites as much as a century earlier. The beginning of EB IV is not based on modeling, but a date of $\sim 2500 \mathrm{BC}$ is suggested, even though it could have commenced earlier.

\section{Radiocarbon Sampling and Analysis}

The overview obtained by combining and analyzing the hundreds of ${ }^{14} \mathrm{C}$ dates that have accumulated for the southern Levant EBA highlights both the strengths and the weaknesses of the data set and of the procedures used to create it. It is worth noting again, and with emphasis, that clusters of seeds in clear association with archaeological contexts provide the most efficacious ${ }^{14} \mathrm{C}$ samples for determining chronology. In our work, the short-lived samples were compared with the charcoal samples, showing a mild old-wood effect that accounted for differences of up to $50 \mathrm{yr}$ in our transition models. In Bayesian analyses, dates derived from charcoal can be used as termini post quem for archaeological strata.

In addition, greater attention must be paid to the quality associations between samples and the archaeological contexts from which the ${ }^{14} \mathrm{C}$ samples originate. In ongoing excavations, microarchaeological methods can be useful in determining which associations are strong or even absolute. Since cultural changes are not necessarily contemporaneous at different sites, multilayered sites should be modeled separately and single-occupation sites should not be included in models but analyzed as single entities. For more accurate determinations of transitions, optimal situations would be to obtain large sets of dates from good contexts, distributed over entire phases.

A benefit of ${ }^{14} \mathrm{C}$ modeling is that large sets of dates related to consecutive stratigraphic units can overcome some of the shortcomings introduced by plateaus in the calibration curve by virtue of the 
constraints imposed by Bayesian analysis. Modeling is an excellent tool in identifying outliers, which, rather ironically, can be very informative for interpreting the archaeological record. They can help in understanding the degree of stratigraphic "noise" in one or another archaeological deposit, as well as site formation processes involved. Thus, any future advance in ${ }^{14} \mathrm{C}$ EBA chronology must be based on analytical quality and material type, as well as on the triad of well-defined cultural horizons, extended, densely sampled stratigraphic sequences, and secure sampling contexts.

\section{ACKNOWLEDGMENTS}

Some of this data was reviewed under the ARCANE project by several members. We wish to thank those who contributed to the understanding of specific ${ }^{14} \mathrm{C}$ sample contexts: Baruch Brandl, Hermann Genz, Amir Golani, Peter Fischer, Sarit Paz, Naama Scheftelowitz, Steve Rosen, and Michael Sebanne, as well as the excavators who have kindly let us use some of the yet-unpublished ${ }^{14} \mathrm{C}$ dates for this paper: Emanuel Eisenberg, Timothy Harrison, and Edwin van den Brink. We are grateful for the valuable comments of the reviewers, who also brought to our attention additional dates that were included in the study. E Braun's contribution to this paper was done while an NEH Fellowship at the W F Albright Institute of Archaeology, Jerusalem, Israel. We wish to thank Lior Regev for assisting with some of the figures and manuscript, as well as Leticia Barda from IAA for preparing the map of the EBA sites with ${ }^{14} \mathrm{C}$ measurements.

\section{REFERENCES}

Adams RB. 2000. The Early Bronze Age III-IV transition in southern Jordan: evidence from Khirbet Hamra Ifdan. In: Philip G, Baird D, editors. Ceramics and Change in the Early Bronze Age of the Southern Levant. Sheffield: Sheffield Academic Press. p 379-402.

Adams B, Porat N. 1996. Imported pottery with potmarks from Abydos. In: Spencer J, editor. Aspects of Early Egypt. London: British Museum Press. p 98-107.

Aharoni Y. 1964. The second season of excavation at Tel Arad (1963). Yediot 28(3-4):153-75. In Hebrew.

Aharoni Y. 1967. Excavations at Tel Arad: preliminary report on the second season, 1963. Israel Exploration Journal 17(4):233-49.

Ambers J, Bowman S. 1998. Radiocarbon measurements from the British Museum: datelist XXIV. Archaeometry 40(2):413-35.

Amiran R. 1969. Ancient Pottery of the Holy Land. Jerusalem: Masada Press.

Anderson Jr RW. 2006. Southern Palestinian chronology: two radiocarbon dates for the Early Bronze Age at Tell el-Hesi (Israel). Radiocarbon 48(1):101-7.

Ashmore P. 1999. Radiocarbon dating: avoiding errors by avoiding mixed samples. Antiquity 73(279):124-30.

Avner U, Carmi I, Segal D. 1994. Neolithic to Bronze Age settlement of the Negev and Sinai in light of radiocarbon dating: a view from the southern Negev. In: Bar-Yosef O, Kra RS, editors. Late Quaternary Chronology and Paleoclimates of the Eastern Mediterranean. Tucson: Radiocarbon. p 265-300.

Avner U, Carmi I. 2001. Settlement patterns in the southern Levant deserts during the 6th-3rd millennia BC: a revision based on ${ }^{14} \mathrm{C}$ dating. Radiocarbon $43(3)$ : 1203-16.
Baines J, Malek J. 1980. Atlas of Ancient Egypt. London: Phaidon.

Barker HBR, Meeks N. 1971. British Museum natural radiocarbon measurements VII. Radiocarbon 13(2): 157-88.

Baumgarten Y. 2004. An excavation at Ashqelon, Afridar-Area J. 'Atiqot 45:161-84.

Bayes TR. 1763. An essay towards solving a problem in the doctrine of chances. Philosophical Transactions of the Royal Society 53:370-418.

Ben-Tor A. 1981. The relations between Egypt and the Land of Canaan during the third millennium B.C. American Journal of Archaeology 85(4):449-52.

Boaretto E. 2007. Determining the chronology of an archaeological site using radiocarbon: minimizing uncertainty. Israel Journal of Earth Sciences 56(2-4): 207-16.

Boaretto E. 2008. In: Golani A. The Early Bronze Age site of Ashqelon, Afridar-Area M. 'Atiqot 60:45-6.

Boaretto E. In press. Radiocarbon Dating of Archaeobotanical Samples from an Early Bronze Age Site of Ashqelon Barnea. IAA Reports. Jerusalem: Israel Antiquities Authority.

Bonani G, Wölfli W. 1991. Radiocarbon dates from area B. In: Kempinski A, Niemeier WD, editors. Excavations at Kabri Preliminary Report of 1990 Season. Tel Aviv: Tel Aviv University. p 8. In Hebrew.

Bonani G, Haas H, Hawass Z, Lehner M, Nakhla S, Nolan J, Wenke R, Wölfli W. 2001. Radiocarbon dates of Old and Middle Kingdom monuments in Egypt. $R a$ diocarbon 43(3): 1297-320.

Bourke S, Zoppi U. 2007. Dating the Cultic Assemblages from the Bronze Age Fortress Temple Complex at 
Pella in Jordan. Progress Report for AINGRA 05013. Sydney: University of Sydney.

Bourke S, Lawson E, Lovell J, Hua Q, Zoppi U, Barbetti M. 2001. The chronology of the Ghassulian Chalcolithic period in the southern Levant: new ${ }^{14} \mathrm{C}$ determinations from Teleilat Ghassul, Jordan. Radiocarbon 43(3):1217-22.

Bourke S, Zoppi U, Meadows J, Hua Q, Gibbins S. 2004. The end of the Chalcolithic period in the south Jordan Valley: new ${ }^{14} \mathrm{C}$ determinations from Teleilat Ghassul, Jordan. Radiocarbon 46(1):315-23.

Bourke S, Zoppi U, Hua Q, Meadows J, Gibbins S. 2009. The beginning of the Early Bronze Age in the north Jordan Valley: new ${ }^{14} \mathrm{C}$ determinations from Pella in Jordan. Radiocarbon 51(3):905-913.

Bowman S. 1990. Radiocarbon Dating. Interpreting the Past. Berkeley: University of California Press.

Braun E. 1996. Cultural diversity and change in the Early Bronze I of Israel and Jordan: towards an understanding of the chronological progression and patterns of regionalism in Early Bronze society [PhD dissertation]. Tel Aviv University.

Braun E. 2001. Proto, Early Dynastic Egypt and Early Bronze I-II of southern Levant: some uneasy correlations. Radiocarbon 43(3):1279-96.

Braun E. 2011a. South Levantine Early Bronze Age chronological correlations with Egypt in light of the Narmer serekhs from Tel Erani and Arad: new interpretations. In: Friedman RF, Fiske PN, editors. Egypt at Its Origins 3. Proceedings of the Third International Conference (Origin of the State. Predynastic and Early Dynastic Egypt). Orientalia Lovaniensia Analecta 205. Leuven: Peeters. p 975-1001.

Braun E. 2011b. Early interaction between peoples of the Nile Valley and the southern Levant. In: Teeter E, editor. Egypt before the Pyramids: The Origins of Egyptian Civilization. Chicago: The Oriental Institute. p 106-22.

Braun E. 2012. On some south Levantine Early Bronze Age ceramic "wares" and styles. Palestine Exploration Fund Quarterly 144:4-31.

Braun E, Gophna R. 2004. Excavations at Ashqelon, Afridar-Area G. 'Atiqot 45:185-242.

Bronk Ramsey C. 2009. Bayesian analysis of radiocarbon dates. Radiocarbon 51(1):337-60.

Bronk Ramsey C, Higham TFG, Owen DC, Pike AWG, Hedges REM. 2002. Radiocarbon dates from the Oxford AMS system: datelist 31. Archaeometry 44(3): 1149.

Bronk Ramsey C, Dee MW, Rowland JM, Higham TFG, Harris SA, Brock F, Quiles A, Wild EM, Marcus ES, Shortland AJ. 2010. Radiocarbon-based chronology for dynastic Egypt. Science 328(5985): 1554-7.

Bruins H, van der Plicht. 2001. Radiocarbon challenges archaeo-historical time frameworks in the Near East: the Early Bronze Age of Jericho in relation to Egypt. Radiocarbon 43(3): 1321-32.
Bunimovitz S, Greenberg R. 2004. Revealed in their cups: Syrian drinking customs in Intermediate Bronze Age Canaan. Bulletin of the American Schools of Oriental Research 334:19-31.

Burleigh R. 1981. Radiocarbon dates. In: Kenyon KM, editor. Excavations at Jericho. Volume 3; The Architecture and Stratigraphy of the Tell. London: British School of Archaeology Jerusalem. p 501-4.

Burleigh R, Matthews K, Ambers J. 1982. British Museum natural radiocarbon measurements XV. Radiocarbon 24(3):262-90.

Burton M, Levy TE. 2001. The Chalcolithic radiocarbon record and its use in the southern Levantine archaeology. Radiocarbon 43(3): 1223-46.

Callaway J. 1972. The Early Bronze Age Sanctuary at Ai (et-Tell). London: Bernard Quaritch Ltd.

Callaway JA, Weinstein JM. 1977. Radiocarbon dating of Palestine in the Early Bronze Age. American Schools of Oriental Research Bulletin 225:1-16.

Carmi I, Segal D. 2000. Radiocarbon dates. In: Finkelstein I, Ussishkin D, Halpern B, editors. Megiddo III The 1992-1996 Seasons. Tel Aviv: Institute of Archaeology of Tel Aviv University.

Cohen R. 1999. Ancient Settlement of the Central Negev. Volume 1. The Chalcolithic Period, The Early Bronze Age I. IAA Reports 6. Jerusalem: Israel Antiquities Authority. In Hebrew.

Cohen SL. 2002. Canaanites, Chronologies, and Connections, the Relationship of Middle Bronze IIA Canaan to Middle Kingdom Egypt. Studies in the Archaeology and History of the Levant 3 . Winona Lake: Eisenbrauns.

Conrad HG, Rothenberg B. 1980. Antikes Kupfer im Timna-Tal: 4000 Jahre Bergbau und Verhuttung in Der Arabah (Israel). Bochum. Deutches BergbauMus. 236 p.

Crane HR, Griffin JB. 1970. University of Michigan radiocarbon dates XIII. Radiocarbon 12(1):161-80.

de Miroschedji P. 1999. Yarmuth: the dawn of city-states in southern Canaan. Near Eastern Archaeology 62(1): 2-19.

de Miroschedji P. 2000. An EB III pottery sequence for southern Canaan. In: Philip G, Baird D, editors. Ceramics and Change in the Early Bronze Age of the Southern Levant. Sheffield: Sheffield Academic Press. p 315-45.

de Miroschedji P. 2006. At the dawn of history: sociopolitical developments in southwestern Canaan in Early Bronze Age III. In: Maeir A, de Miroscedji P, editors. I Will Speak in the Riddles of Ancient Times (Ps 78: 2b): Archaeological and Historical Studies in Honor of Amihai Mazar on the Occasion of his Sixtieth Birthday. Winona Lake: Eisenbrauns. p 55-78.

de Miroschedji P. 2012. Egypt and southern Canaan in the third millennium BCE: Uni's Asiatic campaigns revisited. In: Gruber MI, Ahituv S, Lehmann G, Talshir Z, editors. All the Wisdom of the East, Studies in 
Near Eastern Archaeology and History in Honor of Eliezer D. Oren. Orbisbiblicusetorientalis 255. Fribourg: Academic Press. p 265-92.

Dee MW, Bronk Ramsey C, Shortland AJ, Higham THG, Rowland JM. 2009. Reanalysis of the chronological discrepancies obtained by the Old and Middle Kingdom Monuments Project. Radiocarbon 51(3):106170 .

Dever WG, Lance HD, Ballard RG, Cole DP. 1974. Gezer II: Report of the 1967-70 Seasons in Fields I and II. Jerusalem: Hebrew Union Coll/Nelson Glueck School Biblical Archaeology.

Eisenberg I. Forthcoming. Tel Hebron Final Report of the IAA Excavation 1999. IAA Reports. Jerusalem: Israel Antiquities Authority.

Fischer P. 2000. The Early Bronze Age at Tell Abu elKharaz, Jordan Valley: a study of pottery typology and provenance, radiocarbon dates, and synchronization of Palestine and Egypt during dynasties 0-2. In: Philip G Baird D, editors. Ceramics and Change in the Early Bronze Age Southern Levant. Sheffield: Sheffield Academic Press. p 201-32.

Fishman B, Lawn B. 1977. University of Pennsylvania radiocarbon dates XIX. Radiocarbon 19(2):188-228

Genz H. 2002. Die frühbronzezeitliche Keramik von irbet ez-Zeraqn: Mit Studien zur Chronologie und funktionalen Deutung frühbronzezeitliche Keramik in der südlichen Levante. Wiesbaden: Harrasowitz Verlag.

Gibbs K, Kadowaki SJA, Banning EB. 2010. Excavations at al-Basatin, a late Neolithic and Early Bronze I site in Wadi Ziqlab, northern Jordan. Annual of the Department of Antiquities of Jordan 54:471-6.

Golani A. 2004. Salvage excavations at the Early Bronze age site of Ashqelon, Afridar-Area E. 'Atiqot 45:9-62.

Golani A, Nagar Y. 2011. Newly Discovered Burials of the Chalcolithic and Early Bronze Age I in Southern Canaan: Evidence of Cultural Continuity? In: Lovell JL, Rowan YM, editors. Culture, Chronology and the Chalcolithic: Theory and Transition. CBRL Levant Supplementary Monograph Series Volume 9. Oxford: Oxbow Books. p 84-96.

Golani A, Segal D. 2002. Redefining the onset of the Early Bronze Age in southern Canaan: new evidence of ${ }^{14} \mathrm{C}$ dating from Ashkelon Afridar. In: van den Brink E, Yannai E, editors. In Quest of Ancient Settlements and Landscapes. Tel Aviv: Ramot Publishing. p 135-54.

Greenberg R. 2002. Egypt, Beth Yerah and early Canaanite urbanization. In: Greenberg R. Early Urbanizations in the Levant: A Regional Narrative. London: Leicester University Press. p 213-21.

Greenberg R, Porat N. 1996. A third millennium Levantine pottery production center: typology, petrography and provenience of the Metallic Ware of northern Israel and adjacent region. Bulletin of the American Schools of Oriental Research 301:5-24.

Hauptmann A. 2000. Zur frühen Metallurgie des Kupfers in Fenan/Jordanien. Bochum: Der Anschnitt, Beiheft
11, aus dem Deutschen Bergbau-Museum.

Hedges REM, Housley RA, Bronk CR, van Klinken GJ. 1992. Radiocarbon dates from the AMS system: datelist 14. Archaeometry 34(1):141-57.

Henry DO. 1995. Prehistoric Cultural Ecology and Evolution. Insights from Southern Jordan. New York: Plenum Press.

Holdorf PS. 2010. Comparison of EB IV radiocarbon results from Khirbat lskandar and Bab adh-Dhra. Final Report on the Early Bronze IV Area C Gateway and Cemeteries. Archaeological Expedition to Khirbat Iskandar and its Environs, Jordan, Volume 1. Boston: American Schools of Oriental Research. p 267-70.

Holzer A, Avner U. 2000. Har Shahamon (Desert Kite). Excavations and Surveys in Israel 109:165.

Hornung ER, Krauss R, Warburton DA, editors. 2006. Ancient Egyptian Chronology. Handbook of Oriental Studies. Section One: The Near and Middle East. Boston: Brill.

Joffe A. 1993. Settlement and Society in the Early Bronze Age I and II, Southern Levant. Sheffield: Sheffield Academic Press.

Joffe A, Dessel JP. 1995. Redefining chronology and terminology for the Chalcolithic of the southern Levant. Current Anthropology 36(3):507-18.

Kantor HJ. 1992. Egypt. In: Ehrich R, editor. Chronologies in Old World Archaeology. Chicago: University of Chicago Press. p 3-21.

Kigoshi K, Suzuki N, Fukatsu H. 1973. Gakushuin natural radiocarbon measurements VIII. Radiocarbon 15(1):42-67.

Kitchen KA. 1987. The basics of Egyptian chronology in relation to the Bronze Age. High, Middle or Low? In: Åström P, editor. Acts of an International Colloquium on Absolute Chronology Held at the University of Gothenburg 20th-22nd August 1987, Part 1. Studies in Mediterranean Archaeology and Literature. Gothenburg. p 37-55.

Kitchen KA. 1991. The chronology of ancient Egypt. World Archaeology 23(2):201-8.

Klimscha F. 2009. Radiocarbon dates from prehistoric Aqaba and other related sites from the Chalcolithic period. In: Khalil L, Schmidt K, editors. Radiocarbon Dates from Prehistoric Aqaba and Other Related Sites from the Chalcolithic Period. Prehistoric 'Aqaba. Orient-Archäologie Band 23. Rahden: Verlag Marie Leidorf GmbH. p 363-419.

Lombardo M, Piloto A. 2000. Appendix D: new radiocarbon dates and assessment of all dates obtained for the Early and Middle Bronze ages in Jericho. In: Marchetti N, Nigro L, editors. Excavations at Jericho, 1998. Preliminary Report on the Second Season of Excavations and Surveys at Tell es-Sultan. Quaderni di Gerico 2. Roma: Università di Roma "La Sapienza." p 329-32.

Mazar A. 1992. Archaeology of the Land of the Bible 10,000-586 B.C.E. New York: Doubleday.

Mazar A, de Miroschedji P. 1996. Hartuv, an aspect of the 
Early Bronze culture of southern Israel. Bulletin of American Schools of Oriental Research 302:1-40.

Mazar A, Rotem Y. 2009. Tel Beth Shean during the EB IB period: evidence for social complexity in the late 4th millennium BC. Levant 41(2):131-53.

Oren E, Yekutieli Y. 1992. Taur Ikhbeineh; earliest evidence for Egyptian interconnection. In: van den Brink ECM, editor. The Nile Delta in Transition: 4th-3rd Millennium $B C$. Jerusalem: Israel Exploration Society. p 361-84.

Paz S. 2010. Life in the City: The Birth of an Urban Habitus in the Early Bronze Age of Israel. Tel Aviv: Tel Aviv University.

Philip G. 2001. The Early Bronze I-III ages. In: MacDonald B, Adams R, Bienkowski P, editors. The Archaeology of Jordan. Sheffield: Sheffield Academic Press. p 163-232.

Philip G. 2008. The Early Bronze Age I-III. In: Adams R, editor. Jordan: An Archaeological Reader. London: Equinox. p 161-226.

Philip G, Millard R. 2000. Khirbet Kerak Ware in the Levant: the implications of radiocarbon chronology and spatial distribution. In: Marro C, Hauptmann $\mathrm{H}$, editors. Chronologies des pays du Caucase et de l'Euphrate aux IVe-IIIe millénaires, Actes du Colloque d'Istanbul, 16-19 décembre 1998, Varia Anatolica XI, Institut Français d'Études Anatoliennes d'Istanbul. Paris: De Boccard. p 279-96.

Rast WE, Schaub RT. 1980. Preliminary report of the 1979 expedition to the Dead Sea Plain, Jordan. Bulletin of the American Schools of Oriental Research 240: 21-61.

Rast WE, Schaub RT. 2003. Bâb edh-Dhrâ: Excavations at the Town Site (1975-1981). Eisenbrauns: Winona Lake.

Regev J, de Miroschedji P, Boaretto E. 2012. Early Bronze Age chronology: radiocarbon dates and chronological models from Tel Yarmuth (Israel). Radiocarbon, these proceedings.

Reimer PJ, Baillie MGL, Bard E, Bayliss A, Beck JW, Bertrand CJH, Blackwell PG, Buck CE, Burr GS, Cutler KB, Damon PE, Edwards RL, Fairbanks RG, Friedrich M, Guilderson TP, Hogg AG, Hughen KA, Kromer B, McCormac G, Manning S, Bronk Ramsey C, Reimer RW, Remmele S, Southon JR, Stuiver M, Talamo S, Taylor FW, van der Plicht J, Weyhenmeyer CE. 2004. IntCal04 terrestrial radiocarbon age calibration, 0-26 cal kyr BP. Radiocarbon 46(3): 1029-58.

Reimer PJ, Baillie MGL, Bard E, Bayliss A, Beck JW, Blackwell PG, Bronk Ramsey C, Buck CE, Burr GS, Edwards RL, Friedrich M, Grootes PM, Guilderson TP, Hajdas I, Heaton TJ, Hogg AG, Hughen KA, Kaiser KF, Kromer B, McCormac FG, Manning SW, Reimer RW, Richards DA, Southon JR, Talamo S, Turney CSM, van der Plicht J, Weyhenmeyer CE. 2009. IntCal09 and Marine09 radiocarbon age calibration curves, 0-50,000 years cal BP. Radiocarbon 51(4): $1111-50$
Richard S. 1980. Toward a consensus of opinion on the end of the Early Bronze Age in Palestine-Transjordan. Bulletin of the American Schools of Oriental Research 237(winter):5-34.

Richard S. 1987. Archaeological sources for the history of Palestine: the Early Bronze Age: the rise and collapse of urbanism. The Biblical Archaeologist 50(1): 22-43.

Scheftelowitz N. 2002. Stratigraphy, architecture and tombs I. Area B. In: Kempinski A, Scheftelowitz N, Oren R. Tel Kabri: The 1986-1993 Excavation Seasons. Tel Aviv: Institute of Archaeology, Tel Aviv University. p 19-29.

Schiffer MB. 1986. Radiocarbon dating and the "old wood" problem: the case of the Hohokam chronology. Journal of Archaeological Science 13(1):13-30.

Segal D, Carmi I. 1996. Rehovot radiocarbon datelist V. 'Atiqot XXIX:79-106.

Segal D, Carmi I. 2003. Radiocarbon dates from Horbat Hani (West). 'Atiqot 44:65-6.

Segal D, Carmi I. 2004a. Determination of age using the ${ }^{14} \mathrm{C}$ method on archaeobotanical samples from Ashqelon, Afridar-Area E. 'Atiqot 45:119-20.

Segal D, Carmi I. 2004b. Radiocarbon dates from Area F. 'Atiqot 45:156.

Segal D, Carmi I. 2004c. Rehovot radiocarbon date list VI. 'Atiqot 48:123-48.

Segal D, Carmi I. 2006. Radiocarbon dates. In: Getzov N, editor. The Tel Bet Yerah Excavations, 1994-1995. IAA Reports 28. Jerusalem: Israel Antiquities Authority. p 175-6.

Scharpenseel HW, Pietig F, Sciffmann H. 1976. Hamburg University radiocarbon dates I. Radiocarbon 18(3):268-9.

Shaw 1, editor. 2000. The Oxford History of Ancient Egypt. Oxford: University Press.

Sowada KS. 2009. Egypt in the Eastern Mediterranean during the Old Kingdom. An Archaeological Perspective. Orbis Biblicus et Orientalis 237. Fribourg: Academic Press.

Stadler P, Fischer PM. 2008. Radiocarbon datings. In: Fischer PM, editor. Tell Abu al-Kharaz in the Jordan Valley. Vienna: Austrian Academy of Sciences. p 3238.

Stager LE. 1992. The periodization of Palestine from Neolithic through Early Bronze Age times. In: Ehrich RW, editor. Chronologies in Old World Archaeology. 3rd edition. Chicago: University of Chicago Press. Volume 1:22-41; Volume 2:17-60.

Stuckenrath R, Ralph EK. 1965. University of Pennsylvania radiocarbon dates VIII. Radiocarbon 7:187-99.

Tubb JN. 1988. Tell es-Sa'idiyeh: preliminary report on the firs three seasons of excavation. Levant 20:23-88.

Tubb JN. 1990. Preliminary report on the fourth season of excavation at Tell es-Saidiyeh in the Jordan Valley. Levant 22:21-42.

Vogel JC, Waterbolk HT. 1967. Groningen radiocarbon dates VII. Radiocarbon 9:107-55. 
Weinstein JM. 1984. Radiocarbon dating in the southern Levant. Radiocarbon 26(3):297-366.

Wright GE. 1971. Archaeology of Palestine from the Neolithic through the Middle Bronze Age. Journal of the American Oriental Society 91(2):276-93.

Wuttmann M, Briois F, Midant-Reynes B, Dachy T. 2012. Dating the end of the Neolithic in an eastern Sahara oasis: modeling absolute chronology. Radiocarbon, these proceedings.

Yekutieli Y. 2006. The ceramics of Tel 'Erani, Layer C. Journal of the Serbian Archaeological Society 22: 225-42.
Yekutieli Y. 2007. The relations between Egypt and Canaan in the Early Bronze Age 1-a view from south-western Canaan. Qadmoniot 134:66-74. In Hebrew.

Yizhaq M, Mintz G, Cohen I, Khalaily H, Weiner S, Boaretto E. 2005. Quality controlled radiocarbon dating of bones and charcoal from the early Pre-Pottery Neolithic B (PPNB) of Motza (Israel). Radiocarbon 47(2):193-206.

Zeuner FE. 1956. The radiocarbon age of Jericho. Antiquity 30:195-7. 